\title{
POTENTIAL IMPACT OF INTEGRATING THE STERILE INSECT TECHNIQUE INTO THE FIGHT AGAINST DISEASE-TRANSMITTING MOSQUITOES
}

\author{
R. S. LEES ${ }^{1}$, D. O. CARVALHO² AND J. BOUYER ${ }^{2,3}$ \\ ${ }^{1}$ Liverpool School of Tropical Medicine, Liverpool, United Kingdom \\ Rosemary.Lees@lstmed.ac.uk \\ ${ }^{2}$ Joint FAO/IAEA Division of Nuclear Techniques in Food and Agriculture, \\ International Atomic Energy Agency, A-1400 Vienna, Austria \\ ${ }^{3}$ CIRAD, UMR ASTRE, F-34398, Montpellier, France
}

\section{TABLE OF CONTENTS}

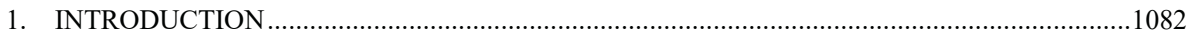

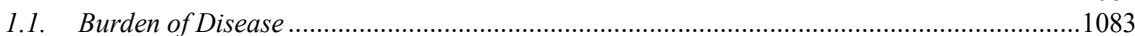

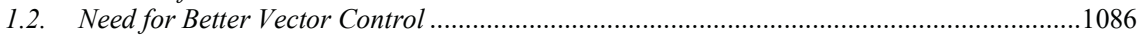

1.3. Integration of the SIT Offers the Potential for Sustainable Mosquito Suppression ...............1087

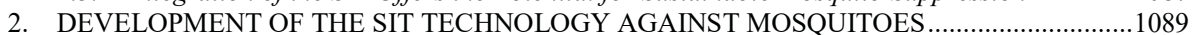

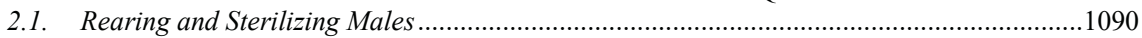

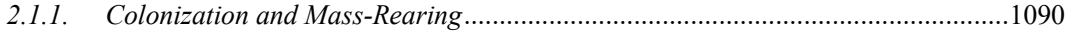

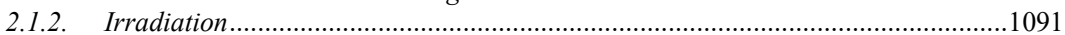

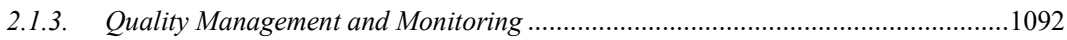

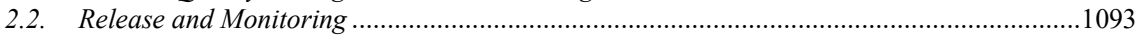

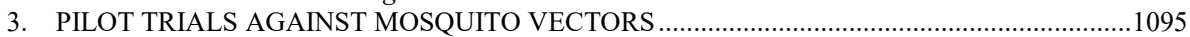

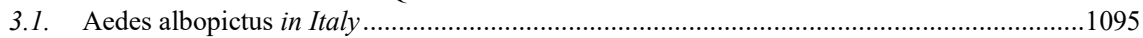

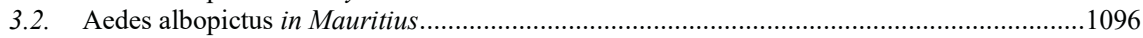

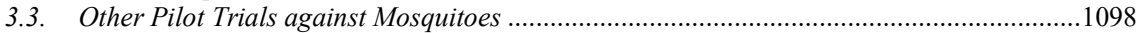

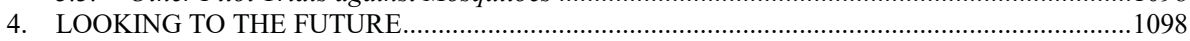

4.1. Need for Scalable and Effective Sex Separation ...........................................................1100

4.2. Combined SIT/IIT Approach to Control Aedes ...........................................................1103

4.3. New Opportunities in the Integrated Management of Mosquito-Borne Diseases

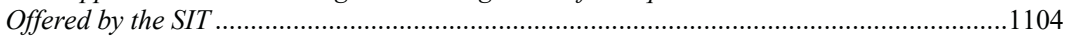

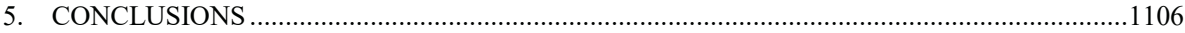

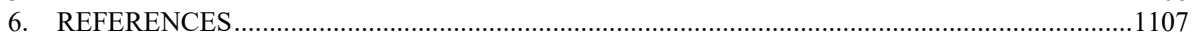

V. A. Dyck, J. Hendrichs and A. S. Robinson (eds.), Sterile Insect Technique. Principles and Practice in Area-Wide Integrated Pest Management. Second Edition.

(C) 2021 IAEA. CRC Press, Boca Raton, Florida, USA. 


\section{SUMMARY}

More than three thousand million people live with the risk of malaria. Due to the widespread resistance of mosquitoes to insecticides and of parasites to chemotherapies, previous gains made in disease reduction are being reversed. In addition to this perennial threat, there is now a rapid invasion of Aedes mosquitoes across the globe and the associated spread of the arboviruses (arthropod-borne viruses) they carry. One half of the world's population is now at risk of dengue, and chikungunya (having emerged from Africa) is an increasing public-health problem in Asia and the Americas. The economic and social costs of these diseases is so great that, in some areas, they have slowed the development of nations. Current vector-control methods are inadequate (especially against container-breeding species) because they are losing their effectiveness, the global burden of mosquito-borne diseases is increasing, and no specific drugs or effective global vaccines are available to treat or prevent the diseases. Therefore, there is a need for additional suppression methods to be applied as part of Integrated Vector Management (IVM). Since the early 2000s, there has been a renewed interest in applying the sterile insect technique (SIT) against mosquito vectors of disease. The explosive outbreaks of the Zika virus (and associated birth defects) across the tropics increased the urgency. The recent availability of technology to rear and release the sterilized males of many mosquito species on a large scale has increased the expectation that the SIT could help reduce the suffering caused by mosquitoborne diseases. Much progress has been made in developing the SIT technology for mosquitoes, based on historic SIT efforts and the experiences gained in the successful large-scale application of the technique against agricultural pest species. The SIT is a suitable technology for suppressing mosquitoes because: (1) they can be mass-reared in a laboratory, (2) natural sexual dimorphism in many species aids sex separation, and (3) females become refractory after mating. There has been a perception that mosquitoes are more vulnerable than many pest species to damage during handling, sterilization, and release. However, technological and methodological improvements can cope with this lower robustness, and indeed take advantage of their smaller size and weight. Nevertheless, the need for perfect sex separation for male-only release to preclude any biting and disease transmission by released females, remains a technical bottleneck to scaling the SIT beyond small-scale pilot trials. As a remedy for this, genetic sexing strains are being developed. However, until they are available, combining the SIT with cytoplasmic incompatibility conferred by Wolbachia infection (incompatible insect technique (IIT)) has been proposed as an advantageous strategy. The advantage of including the IIT is that Wolbachia infection may prevent potential disease transmission by any released females, whereas sterilization guarantees that such females cannot reproduce, avoiding the loss of the cytoplasmic incompatibility due to Wolbachia establishment in the target population. Another advantage of simultaneous IIT use is that it enables the radiation dose to be minimized. Other challenges remain, particularly in release technology and quality control. Nevertheless, in recent years, pilot trials have been conducted or have been initiated, e.g. China, Germany, Greece, Italy, Mauritius, Mexico, Singapore, and Thailand, achieving encouraging results in suppressing adult populations of Aedes species. Area-wide releases, focused on urban and suburban settings, appear particularly promising in terms of sustainable and cost-effective IVM of Aedes vectors (eventually provided commercially by the private sector) because they can protect many people concentrated in relatively small areas. In the case of Anopheles vectors, the SIT may become a useful complementary tool, especially against outdoor-biting species which are not well-controlled by mosquito nets.

\section{INTRODUCTION}

Mosquito-transmitted dengue is now the world's most common mosquito-borne viral disease; over the last 50 years the incidence has grown more than 30-fold (Bhatt et al. 2013). Dengue viruses are estimated to infect about 400 million people per year, and over half of the world's population is at risk of the disease. Moreover, chikungunya virus emerged from Africa in the mid-2000s, and spread across Asia and the Americas in 2013 (Mayer et al. 2017). Due to the increasing spread of invasive mosquito species (Kraemer et al. 2015), these arboviruses were already becoming a major international public-health concern, even before Zika virus outbreaks occurred in the South Pacific in 2013 and in the Americas in 2015 (Mayer et al. 2017). Epidemics of the Zika virus in the Americas were associated with cases of microcephaly and other congenital 
abnormalities. On 1 February 2016 the World Health Organization (WHO) declared a public-health emergency of international concern. To date there are no drugs or effective global vaccines available to treat or prevent Zika; this situation led to calls for an urgent response against its Aedes vectors. Even though one of the best vaccines ever developed exists for yellow fever (another arbovirus), it is re-emerging in some countries (including Angola, Brazil, China, Democratic Republic of Congo, and Kenya (Zwizwai 2017)).

Subsequent to a major expansion of its geographical range, Aedes aegypti (L.) is the most important vector of arboviruses worldwide, particularly in tropical and subtropical urban settings (Mayer et al. 2017). Aedes albopictus (Skuse) is also a major public-health concern because it is a very good vector of several arboviruses including dengue, chikungunya, and Zika (Mitchell 1995). The epidemiological risks associated with Ae. albopictus are increasingly great in Europe, where significant disease outbreaks are now occurring (Gossner et al. 2018). While arboviruses are increasing in impact and notoriety, 3.2 thousand million people remain at risk of malaria, transmitted by Anopheline mosquitoes; in 2016 alone, an estimated 216 million new cases of malaria and 445000 deaths occurred (WHO 2017b).

\subsection{Burden of Disease}

Seven of the major vector-borne diseases (malaria, lymphatic filariasis, leishmaniasis, dengue, Japanese encephalitis, yellow fever, and Chagas' disease) share a largely overlapping pattern of global distribution; many parts of the world are at risk of up to six of these (Fig. 1) (Golding et al. 2015). Controlling the mosquito vectors would simultaneously combat several co-localized diseases, improving the benefit/cost ratio and sustainability of control efforts, particularly Integrated Vector Management (IVM) programmes, which could include a sterile insect technique (SIT) component. Alongside the human suffering (morbidity and mortality) caused directly by mosquitoborne diseases, they also exert a high financial burden -- direct costs of treatments and prevention activities, and indirect costs through loss of human productivity and subsequent impact on a region's economy. The concentration of malaria cases in Africa means that malaria in particular constitutes a major obstacle to sustainable development and poverty eradication on the continent.

The cost of treating cases of disease can vary greatly depending on the economic and social setting. The direct and indirect costs may fall on the state, on the patients and their families, or on both. In Ghana, for example, the treatment cost for each malaria episode varies from USD 5.70 to 48.73 , depending on the severity of disease; the household is responsible for $55 \%$ of the treatment cost. Indirect costs, such as a funeral, can in some African countries be equivalent to one year's total household income (Sicuri et al. 2013). The Philippines carries the fourth-highest burden of dengue cases in South-East Asia; an analysis by Edillo et al. (2015) estimated that over 840000 clinically diagnosed cases led to direct medical costs of USD 345 million (USD 3.26 per capita). Thirty-five percent of cases were treated as outpatients, representing $10 \%$ of indirect costs, compared with the $65 \%$ of patients who were hospitalized and constituted $90 \%$ of direct costs. 


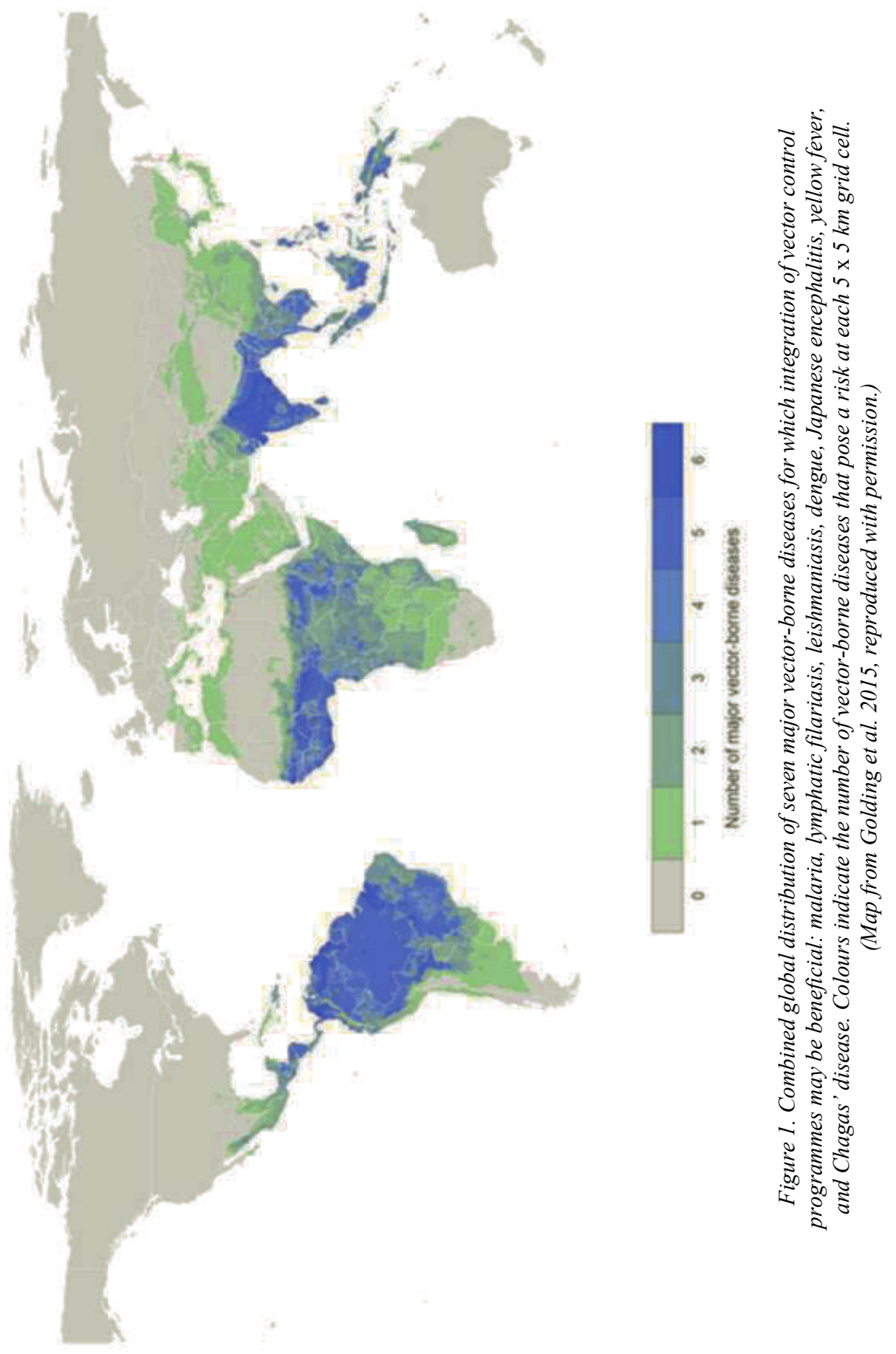


The cost of fighting dengue in 18 countries at purchasing power parity (PPP) was calculated at about USD 3.3 thousand million in 2015; using standardized PPP costs permits comparing socio-economic impacts in the different countries (Oliveira et al. 2019).

The economic burden of vector-control costs, in an attempt to reduce or prevent cases of disease, needs to be factored into estimates of the cost of disease to a country or region. To the USD 102.2 million direct cost of treating the almost 40000 cases of dengue reported annually in Malaysia from 2007 to 2012, another USD 73.5 million $(0.03 \%$ of Gross Domestic Product (GDP)) need to be added for the National Dengue Vector Control Programme, mostly for adulticidal fogging, increasing the cost by $72 \%$ (Raviwharmman Packierisamy et al. 2015).

Vector-control costs can apply even where a disease is not yet a problem or has previously been brought under control, e.g. countries (such as Mauritius) which are at risk from importation of arboviruses due to their high inflow of international visitors (Beesoon et al. 2008; Ramchurn et al. 2009) or those countries at risk of invasion by Aedes vectors. A balance must be made between potential disease costs and preventive vector control efforts. As the Zika virus was spreading through the Americas, the US president requested USD 1.8 billion from Congress in February 2016 to combat Zika in Costa Rica and Brazil, expenditure which was found to be justified in a study by Alfaro-Murillo et al. (2016). The judgement was based on estimated probabilities of microcephaly in babies born to infected mothers and direct medical costs, which both vary by country, and the loss of Disability-Adjusted Life Years (DALYs) per case of microcephaly (29.95 DALYs) and of Guillain-Barré syndrome (1.25 DALYs).

The wider benefits of disease reduction or eradication may be significant. A study conducted in Ghana into the economic-burden impact of malaria mentions that a $1 \%$ increase in malaria morbidity reduces economic growth by $0.41 \%$ (Asante and Asenso-Okyere 2003). Due to malaria, each business in the nation lost on average about a month's productivity per year; this corresponds to a drastic decrease in average income. A dynamic macrosimulation model to estimate the effects of eradicating malaria shows that higher economic development can be achieved in the long-term (within 30 to 50 years) from malaria eradication (Ashraf et al. 2009).

While the burden of agricultural pest insects is usually felt by individual growers and sector cooperatives, the burden of vector-borne diseases is felt by the whole population; therefore, the management of such diseases is commonly the responsibility of local organizations (including non-governmental mosquito control districts (Foley IV et al. 2021)) or supplemented by governments as part of their social policy, where it is a constitutional requirement to provide health care. Tang et al. (2004) developed a framework outlining for the USA the ten coordination and regulatory roles that government may play in health-care quality (which could be applied in any country):

(1) purchase health care, (2) provide health care, (3) ensure access to quality care for vulnerable populations, (4) regulate health care markets, (5) support acquisition of new knowledge, (6) develop and evaluate health technologies and practices, (7) monitor health care quality, (8) inform health care decision-makers, (9) develop the health care workforce, and (10) convene stakeholders from across the health care system. 
Each role proposed above would have an impact on the control of neglected diseases. In facing the continuous increase in the number of cases and disease expansion to new areas, item six highlights how critical it is to develop an effective contribution to reducing the number of transmitted cases over time -- by incorporating new strategies and control methods for vector-borne disease control (Araújo et al. 2015; Bourtzis et al. 2016).

Various countries have developed their own guidelines and protocols to deal with vector-borne diseases (based on guidelines developed by the WHO (WHO 2009, 2012)) in which they formulate evidence-based strategies and policies. For example, the Brazilian health ministry developed the National Dengue Control Plan (PNCD), operating since 2002. It comprises a great range of activities and instructions in an effort to reduce the number of dengue cases all over the country. This plan evolved after the first attempt to eradicate the mosquito in the 1970s -- aggregating and developing strategies based on different approaches including epidemiological and entomological surveillance, frequent house inspections, and insecticide application (Braga and Valle 2007). Until now, the PNCD's objectives have not been fully achieved, and the fact that dengue epidemics can still be expected every year illustrates the need for a full review and evaluation of the strategies and control methods applied. There are local problems related to achieving full implementation of the plan (a result of insufficient support from stakeholders), in addition to growing resistance to the commonly used temephos larvicide and deltamethrin adulticide (Valle et al. 2019), and the general challenge of eradicating populations of containerbreeding Aedes vectors. Brazil alone always represents more than 95\% of the number of dengue cases in Latin America (Pessanha et al. 2009; Salles et al. 2018). Until effective universal vaccines, and safe, effective, and inexpensive drugs, are developed and become available, control of the mosquito vectors of disease is likely to be the most effective method of reducing cases of disease and controlling their spread.

\subsection{Need for Better Vector Control}

Currently most mosquito control strategies rely primarily on the use of insecticides, but with the increasing spread and significance of resistance in vectors of malaria (Ranson and Lissenden 2016) and arboviruses (Ranson et al. 2010; Moyes et al. 2017) there is a need for sustainable tools that enhance the arsenal against key vectors, particularly in the face of public concern about the human health and environmental impact of widespread insecticide use. Although great gains have been made in reducing the burden of malaria (e.g. there were 20 million fewer malaria cases in 2017 than in 2010 (WHO 2018)), these gains have been achieved through applying artemisinin combination therapies (ACTs) and especially insecticide-treated bednets (ITNs). The 2018 World Malaria Report suggested that these gains are being reversed; no significant progress was made in reducing cases between 2015 and 2017 -- due in large part to drug and insecticide resistance becoming increasingly established and widespread (WHO 2018).

In its global vector control response 2017-2030, the WHO pointed out the urgent need for the development and integration of innovative mosquito control methods, including the SIT, particularly against Aedes vectors (WHO 2017a). A major 
advantage of suppressing a mosquito vector population with such an integrated approach is that it can address several diseases at once; different diseases, such as arboviruses, are often transmitted by the same Aedes vectors, whereas other approaches, e.g. vaccination, need to be developed for each new emerging disease.

The behavioural ecology of anthropophilic mosquitoes, and in particular their use of disseminated microhabitats as oviposition sites, challenges the integrated control of these insects in many countries and climatic conditions, and prohibits a satisfactory level of population reduction (Reiter 2016). Moreover, the application of many insecticides is more and more restricted worldwide; this reduces the available vector control options, particularly in the face of spreading resistance against all but the newest classes of insecticides in vectors of both malaria (Sokhna et al. 2013) and arboviruses (Ranson et al. 2010; Grigoraki et al. 2017; Pichler et al. 2018). In addition, insecticide-treated bednets are not effective in combating Aedes vectors (which are active during the day).

Therefore, new techniques to control mosquitoes are under development and being evaluated in the field, including genetic control strategies targeting the reproductive capacity of disease-transmitting mosquitoes (McGraw and O'Neill 2013; Lees et al. 2015; Bourtzis et al. 2016; Flores and O’Neill 2018). Amongst these, the SIT and the incompatible insect technique (IIT) show great promise (Oliva et al. 2014).

\subsection{Integration of the SIT Offers the Potential for Sustainable Mosquito Suppression}

Pilot trials against mosquitoes started in about 1960 in the USA, with the goal of assessing the potential of the SIT to reduce populations of Ae. aegypti and Anopheles quadrimaculatus Say, but in both cases there was no evident population suppression in the target areas after 43-48 weeks of releases of sterile males (irradiated with gamma rays) (Morlan et al. 1962; Weidhaas et al. 1962). Many other pilot projects took place with various mosquito species in various countries using different rearing protocols, irradiation sources, and methods of sterilization (chemosterilization, translocations, inversions, and cytoplasmic incompatibility (CI)) (Benedict and Robinson 2003; Dame et al. 2009; Klassen et al., this volume). Some were able to demonstrate suppression and even elimination/eradication of the target population, e.g. elimination of Anopheles albimanus Wiedemann in El Salvador (Breeland et al. 1974; Dame et al. 1974).

Interest in applying the SIT against mosquitoes had waned since these intial trials in the 1960s and 1970s. Rather than technical failure, this was due largely to political instability affecting their implementation and insufficient practical governmental support (Klassen et al., this volume). Moreover, in view of the availability of new insecticides, mosquito control has relied heavily on the use of a limited number of insecticides. Recently, there has been a resurgence of interest due to: (1) increased pressure exerted by emerging arboviruses and the spread of resistant malaria, (2) the loss of current methods of control because of malaria resistance to drugs and resistance to insecticides in both Anopheles and Aedes, and (3) the availability of molecular techniques that have enabled the development of improved strains for the SIT (Bourtzis and Hendrichs 2014; Bourtzis and Tu 2018; FAO/IAEA 2018c; Lutrat et al. 2019) and made alternative versions of genetic control possible (Alphey 2014). 
Releasing insects sterilized by ionizing radiation has been a very important method for the area-wide suppression, containment, and even eradication of major insect pest populations (Klassen et al., this volume). Given the experiences obtained in those programmes applying the SIT, there is reason to believe that it could also be applied -in combination with other control methods as part of an area-wide integrated pest management (AW-IPM) approach -- to suppress disease vectors below the threshold required for disease transmission. Building on previous experiences in the 1960s and 1970s to develop the SIT for disease vectors, many parameters have been investigated to better understand, enable and optimize the application of the SIT against mosquitoes, including mass-rearing procedures, sterilization methods, transport and release methods, and trapping systems (Pepin et al. 2013; Puggioli et al. 2013; Balestrino et al. 2014a, b; Carvalho et al. 2014; Codeço et al. 2015; Lees et al. 2015; Eiras et al. 2018; Bakri et al., this volume; Dowell et al., this volume; Parker, Mamai et al., this volume; Parker, Vreysen et al., this volume; Vreysen, this volume). Part of the development of the SIT against mosquitoes has also been based on the experiences of successful programmes against other insects, e.g. those against Ceratitis capitata (Wiedemann) in the USA, Guatemala, Mexico, and Chile, and Cochliomyia hominivorax (Coquerel) in Central and North America, as well as Libya (Enkerlin, this volume; Klassen et al., this volume; Vargas-Terán et al., this volume). However, more research and testing need to be done before "mosquito SIT" reaches the same level of development as these programmes (Krafsur 1998; Vargas et al. 2008; Enkerlin et al. 2015).

Several features of mosquito biology make mosquitoes suitable targets for the SIT (Beier et al. 2014). Most of the key mosquito disease vectors can be colonized and reared in the laboratory, adapting to feeding on artificial larval diets and taking blood meals through artificial membranes. Therefore, the production of sufficient numbers to achieve an overflooding release ratio is feasible, even if reducing natural population densities using other complementary suppression techniques will often be necessary against mosquitoes, particularly the reduction of larval populations and habitats (Mangan and Bouyer, this volume).

Sexual dimorphism, particularly in Aedes species, can be exploited to help remove females prior to sterilization and release of males, which is an essential requirement for applying the SIT against mosquitoes -- females are the disease vectors, and releasing even small numbers that may transmit disease is problematic for the public and regulators, even if not for technical efficacy.

In comparison with fruit and tsetse flies, mosquitoes are smaller and lighter, making the challenges of handling, transport, and release more tractable (especially to take advantage of new technologies such as automated release from unmanned aerial vehicles (UAVs) (Dowell et al., this volume)). However, their small size also confers some fragility; this must be taken into account to prevent a reduction in survival or quality of released males. Finally, female mosquitoes are mostly refractory to remating -- not an absolute requirement of the SIT but beneficial in reducing the numbers for, and frequency of, release required to induce sterility in the female population (Lance and McInnis, this volume; Whitten and Mahon, this volume).

The container-breeding species, such as Ae. aegypti and Ae. albopictus, are particularly challenging to control because their life cycle relies on oviposition in 
small, and often temporary, sources of water. To mitigate the risks of a whole egg batch being lost due to a small body of water drying out before the offspring can emerge and escape, and also predation or competition for space or nutrition, an Aedine female will lay her egg batch, up to 100 eggs per gonotrophic cycle, in multiple sites. Many of those sites (such as discarded drink cans or tree holes) are very small and difficult to target with chemical control, and many are difficult to remove or treat (such as water butts used to collect rain water in areas of unreliable piped-water supply or buckets in fishing communities), and may be located in urban sites which are not amenable for control, e.g. abandoned lots or balconies of apartments in highrise buildings. This cryptic behaviour also means that females often rest in locations which are not reached by insecticide applications (Dzul-Manzanilla et al. 2017). The advantage of sterile males is that they will locate mates, which then will lay nonviable eggs, and negate the need to find and treat these hard-to-reach oviposition sites. Increasing global trade and urbanization, as well as reliance on disposable containers without sufficient waste disposal infrastructure in many areas affected by mosquitoborne disease, help explain the rapid growth in distribution of Aedes vectors. In this context, the reliance on the dispersal of sterile males rather than human operators is an important advantage of control efforts that integrate mosquito release over other methods; a similar advantage applies to autodissemination stations for juvenile hormones.

In the case of Anopheles females, these are targeted by conventional vector-control methods while they are trying to take a blood meal through an insecticide-treated bednet or resting on a wall treated with indoor residual spray (IRS), but those that remain in untreated houses or communities will be unaffected. Moreover, some exophilous species (such as Anopheles arabiensis Patton) that bite mainly outside will not be impacted by these methods. One major benefit of SIT application against Anopheles mosquitoes, in particular An. arabiensis which is the sole vector of malaria in most of its area of distribution, is that human operators do not need to find and treat these sites or target every mosquito, but instead male mosquitoes are released to seek out and sterilize females, whose eggs (wherever she lays them) will then be sterile.

\section{DEVELOPMENT OF THE SIT TECHNOLOGY AGAINST MOSQUITOES}

Increasing interest in applying the SIT, and other control methods relying on the largescale rearing and release of insects, has led to a rapid improvement in the available technology and methodology to mass-rear, sterilize, assess the quality of, and release and conduct surveillance on, Aedes and Anopheles mosquitoes (Benedict et al. 2009a; Lees et al. 2015). A significant requirement of applying the SIT against mosquito vectors of disease is the need for male-only release, not only to maximize the efficacy of releases and the efficiency of rearing efforts, as in other insects (Franz et al., this volume; Häcker et al., this volume), but also for the public perception and regulatory challenges surrounding the release of even a small number of potentially diseasetransmitting females. Pilot trials of the SIT and associated techniques have been conducted or initiated in recent years in a number of settings, against both genera of mosquitoes, and evidence of the potential for the SIT to suppress mosquito populations is being produced. 


\subsection{Rearing and Sterilizing Males}

\subsubsection{Colonization and Mass-Rearing}

The need for effective colonization and rearing to maintain essential qualities in mosquitoes released for vector control have been reviewed by Benedict et al. (2009b). Colonization and establishment of a new mosquito colony is a painstaking process (FAO/IAEA 2017a, 2018b). Blood-fed females, or immature developmental stages, are collected from a field site where the species of interest is likely to dominate, and individual families are reared while morphological and/or molecular analysis is used to confirm the species. Conspecific families can then be pooled to establish a colony which is often small, and must go through a bottleneck as it becomes adapted to artificial rearing conditions, particularly feeding from an artificial membrane instead of a natural host. Once a colony is established and stabilized, laboratory-adapted mosquitoes are relatively amenable to large-scale rearing, though for a release programme to be efficient each element of the rearing process must be optimized (Parker, Mamai et al., this volume).

Key to affordable production of high-quality adults is the selection of a larval diet which provides all the nutrients needed by developing larvae to grow and establish the nutritional reserves they will require as adults for foraging and mating. Ideally, these should consist of locally available ingredients, be reliably available and of a consistent quality, and even if inexpensive yet still effective in producing high-quality adults (Khan et al. 2013 give Anopheles stephensi Liston as an example). A well-proven diet (consisting of tuna meal, bovine-liver powder, and vitamin mix) is effective for rearing An. arabiensis (Damiens et al. 2012), Ae. albopictus (Puggioli et al. 2013), and Anopheles gambiae Giles (Yahouédo et al. 2014). The addition of Brewer's yeast increases the protein content; it is particularly helpful for improving sexual dimorphism in Aedes rearing (Balestrino et al. 2014a). Given the cost and difficulty in obtaining bovine-liver powder, alternative diets have been validated (e.g. Bimbilé Somda et al. 2017), and other cheaper proteins, e.g. insect proteins, are also being developed (Bimbilé Somda et al. 2019).

Since they have an aquatic larval stage, rearing mosquitoes is more labourintensive than other insect species targeted by the SIT. In addition, the pupal stage, lasting only 24-48 h, must be collected and transferred to a cage before adult emergence. Therefore, some level of automation and large-scale equipment for larvae and adults are required to prevent labour costs from becoming prohibitive. A tray-andrack system (consisting of 50 trays stacked in one rack for easy filling using piped water, seeded with first-instar larvae, reared to pupation, then tilted to recover pupae for transfer to adult cages) has been validated to rear up to $200000 \mathrm{An}$. arabiensis larvae (Balestrino et al. 2012) and about 900000 Ae. albopictus larvae (Balestrino et al. 2014b). Accurate quantification of eggs or larvae used to seed a rearing tray is critical because density-dependent competition acts at the larval stage (affecting the speed and synchronicity of development, the size and nutritional status, and hence the performance of the resulting adults). Trays can be filled in a standardized way using a larval counter (Mamai et al. 2019). Once the trays have been tilted, Anopheles pupae can be separated from remaining larvae (on the basis of their different buoyancy) using a cold-water vortex system (Balestrino et al. 2011), and Aedes pupae are 
separated using the Fay-Morlan separator (Focks 1980). Pupae are quantified volumetrically, and then the required number is transferred to adult emergence cages. In China and Singapore, ongoing programmes recover $70-80 \%$ of male pupae in only one tilting event, and sex separation is very efficient (only $0.3 \%$ female contamination). An automatic sex sorter based on a robotized Fay-Morlan separator has been developed by the Wolbaki company, with the same efficiency and a throughput of up to 150000 pupae per hour (Xi, Z., personal communication).

Adult cages, inspired by those used for mass-rearing fruit flies, have been validated for up to 25000 Ae. albopictus (Balestrino et al. 2014a; FAO/IAEA 2017b) or 15000 An. arabiensis (FAO/IAEA 2017a) pupae. Adults must be blood-fed so that females can develop eggs. Adults are blood-fed using a Hemotek membrane feeder modified for mass-rearing (Damiens et al. 2013). Anopheles eggs are collected in water on the bottom of the oviposition cage which is then flushed out (Maïga et al. 2016); Aedes eggs are laid on wet filter paper which can then be removed and dried for storage (Zheng et al. 2015). Eggs can be quantified at this stage (Zheng et al. 2015; Maïga et al. 2016) before they are stored (Aedes only) or hatched. Mass-rearing using this system does not appear to impact male quality significantly (Soma et al. 2017) as judged in a laboratory setting. A new cheaper mass-rearing cage for Aedes has also been validated recently; it costs $90 \%$ less than the former IAEA reference cage and can be produced locally in any country (Maïga et al. 2019). Alternative designs for mass-rearing cages are also proving to be effective (Zhang et al. 2018).

It is essential to separate males (destined for release) from females (potential disease vectors). A perfect method for sexing mosquitoes on a mass-scale has not yet been developed (Gilles et al. 2014), although promising methods are being evaluated (section 4.1.). Nevertheless, currently Aedes can be separated on the basis of sexual dimorphism (differential speed of development and pupal size) (Fay and Morlan 1959; Focks 1980). In addition, the mass-removal of female Anopheles can be achieved by spiking blood meals with toxicants such as ivermectin (Yamada et al. 2013).

\subsubsection{Irradiation}

There is a perception by some that mosquitoes are more susceptible to somatic damage caused by irradiation (with the resulting reduction in performance) than other species targeted by the SIT (Bakri et al., this volume). There are reports from historic mosquito SIT projects that failures were due to poor male performance (Dame et al. 2009). Nevertheless, it is possible to select a suitable dose to induce sufficient sterility without inflicting unacceptable somatic damage, although rearing is key to ensuring a consistent high-quality output of sterile males for release (Parker, Vreysen et al., this volume). A key observation during historic mosquito SIT releases (Darrow 1968) -that field-collected Culex tarsalis Coquillett males subsequently irradiated as pupae were competitive following re-release, unlike mass-reared and irradiated males -points to the mass-rearing and handling process, and not irradiation, as the more important factor impacting male-mating success.

At the present time, sterile males for release are obtained by irradiating pupae -they are more easily handled and less damaged by radiation than adults (Helinski et al. 2006, 2009). However, strong density-dependent efficiency related to water content and anoxia suggests a method for irradiating chilled compacted adults (that is 
presently under development) will provide better results (H. Yamada, personal communication). On the other hand, pupae can be irradiated at a high density in a small volume of water, minimizing the volume to be irradiated and thereby increasing the uniformity of dose. Protocols and dose-response relationships have been established (to achieve an optimal balance between a high level of sterility and a low impact on male performance) for Ae. albopictus (Balestrino et al. 2010), An. stephensi Liston (Akram and Aslamkhan 1975), Anopheles pharoensis Theobald (Wakid et al. 1976), and An. arabiensis (Helinski et al. 2006). Even though gamma irradiators are commonly available, X-ray irradiation offers a more convenient and less costly alternative, with lower security requirements (Ndo et al. 2014; Yamada et al. 2014; Bakri et al., this volume).

\subsubsection{Quality Management and Monitoring}

Quality management and monitoring of sterile males are critical for the SIT -- to ensure good mating performance and that released males are competitive (Parker, Vreysen et al., this volume; Vreysen, this volume). Quality-control monitoring of rearing conditions is also essential to assure sexual dimorphism in Aedes, synchronous pupal production, consistent productivity and quality, and a reliable number of adults for release (Parker, Mamai et al., this volume; Parker, Vreysen et al., this volume). Regular measurement of important life history traits and mating competitiveness is critical in a colony reared for release. Rearing should be as standardized as possible to ensure consistent quality of material for release, and predictable synchronized development. In Aedes colonies it is important to maximize sexual dimorphism (key to sex-separation). Parameters such as water temperature and larval density must be optimized to consistently produce high-quality adults (Mamai et al. 2018).

A useful method for assessing if rearing conditions are optimal for a given species in a given setting was described by Valerio et al. (2016). To quantify and help minimize the impact of mass-rearing, irradiation, and handling on sterile male mosquitoes, several methods to judge the consistency, quality, and predicted performance following release have been suggested. The relative impact of different handling treatments, and combinations of different parameters, could be estimated by comparing the longevity of exposed males (Chung et al. 2018; Culbert et al. 2018b). Longevity is an important parameter of released males, also sometimes used as a proxy measure of quality.

Balestrino et al. (2017) proposed for Aedes pupae a system of quality control based on flight performance (an improvement on the conventional flight cylinder), and a further development has been designed (Fig. 2), to measure the flight ability of adult mosquitoes; it may be the most practical and robust of the tests for proxies of success. This parameter has been validated as a predictor of survival (a product of being able to forage for food and evade predators) and mating capacity in Ae. aegypti (Culbert et al. 2018a). However, it may be necessary to assess more than one quality indicator to fully understand the impact of colonization, mass-rearing, and manipulations on the overall quality of sterile males (Poda et al. 2018).

Semi-field experiments have demonstrated the ability of sterile male mosquitoes to attract and compete for mates (e.g. Howell and Knols 2009; Bellini et al. 2013a; Madakacherry et al. 2014; Yamada et al. 2014). An. arabiensis adults transported by 
air survived and competed for matings to an acceptable degree in field cages near the intended release site in Sudan (Helinski et al. 2008). Although it is difficult to judge the effect of irradiation and other manipulations in an open field setting, this is a valuable step in evaluation. Field observations of sterile An. arabiensis males participating in swarms within $2 \mathrm{~h}$ of release (Ageep et al. 2014) is a very encouraging measure of the potential success of applying the SIT to control these mosquitoes.
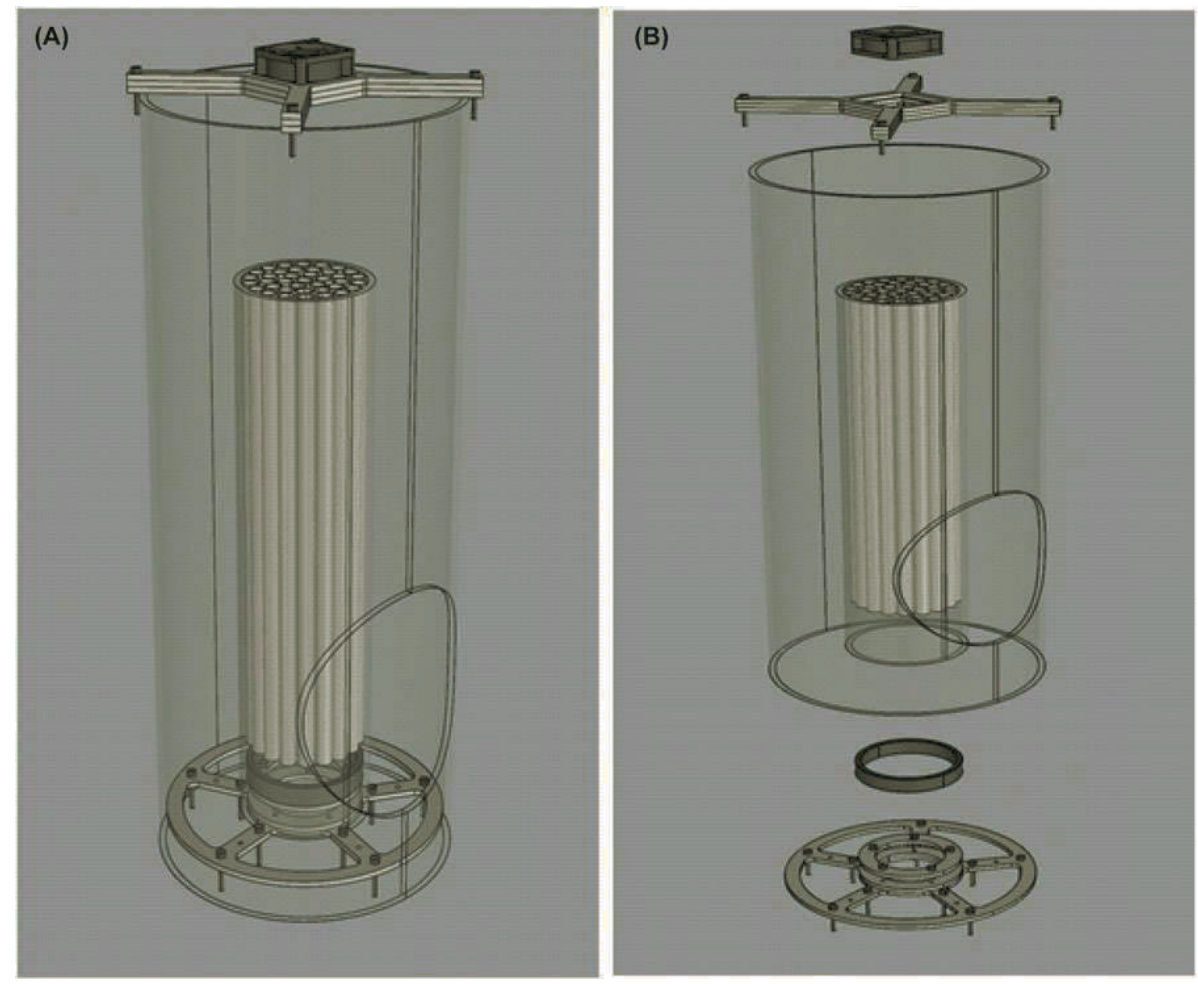

Figure 2. A: Flight test device; B: Device showing components. (Drawings from Culbert et al. 2018 , reproduced with permission.)

\subsection{Release and Monitoring}

Until now the pilot releases of sterile male mosquitoes have been small enough to permit manual release from small plastic containers. Male pupae emerge directly into these containers; they are transported to the field and opened by hand at set ground release points to release the males. This method of release has been used in all of the SIT field pilots until now, as well as in the release of 10000 transgenic Ae. aegypti males per week in Juazeiro, Bahia, Brazil as part of a RIDL (Release of Insects carrying a Dominant Lethal) suppression trial (Carvalho et al. 2015; Häcker et al., this volume). However, the large-scale releases required for operational application of the SIT will necessitate more sophisticated methods of handling, transport, and release, 
i.e. methods that are less labour-intensive and have the capacity to be standardized between sites. The most likely scenario is that adult males will be chilled, loaded into a release device with some level of compaction, and released either aerially or from a motorized vehicle (FAO/IAEA 2014; Chung et al. 2018). In some situations, existing infrastructure may be used, e.g. designing a release device and strategy that utilizes the coverage of large cities by bus routes, or shipping sterile mosquitoes from rearing facility to release site by commercial courier (Mains et al. 2019). Release by UAVs will probably be used to reach areas that are not reliably accessible by road, such as dense favelas or isolated rural hotspots, and importantly to increase the speed of release and uniformity of coverage while reducing costs (Benavente-Sánchez et al. 2021; Dowell et al., this volume).

It is important that release procedures do not unduly damage the males or impact their subsequent performance and survival. Laboratory studies show that mosquitoes are damaged to some degree by chilling, packing, compaction, and release into simulated field conditions (Chung et al. 2018; Culbert et al. 2018a, b). However, some degree of chilling improves survival during compaction (Chung et al. 2018), and parameters such as the chilling temperature can be optimized to minimize the impact. Also, conditions can be optimized by ensuring sufficient ventilation during chilling and transport. For example, the best chilling-temperature range for the transport of compacted An. arabiensis adults is $8-11^{\circ} \mathrm{C}$ (Culbert et al. 2017). Aedine mosquitoes appear to be more robust than Anophelines, and the time of release is likely to be more critical in the latter case.

For an SIT project to be effective, sufficient sterile males must be released in relation to the target population. In an efficient programme, males should be directed to the target area at a fine scale; this requires an understanding of the behaviour, size and spatial distribution of the population before intervention (Lees et al. 2014). Such data are also crucial in monitoring the progress, and demonstrating the success, of the project as it progresses (Vreysen, this volume). During the planning and development phase of an SIT project, it is important to trap male mosquitoes (during mark-releaserecapture experiments) to make assessments about the survival of released males, distance dispersed, and level of mating competitiveness. Ongoing monitoring of the fate of released males, and the size of the target population, is necessary as an SIT programme progresses. The benefits of detailed population data are increased by making releases assisted by automated geographic information systems (GIS) (Bouyer et al., this volume). Software is available which allows releases to be tailored according to real-time surveillance data for maximum efficacy.

Since female mosquitoes are the vectors of disease, most existing traps have been designed to collect females for surveillance, and in some cases for control. It is necessary to produce male-specific tools, or to adapt the timing, location or baiting of traps to target males specifically. For Aedes surveillance, males and females can be collected indoors using aspirators. The BG-Sentinel trap is effective for collecting males, but most of the effective traps attract only gravid females. Thus, there is an especially urgent need for effective methods to survey Anopheline mosquitoes (Batista et al. 2019; van de Straat et al. 2019). The CDC light trap often catches few Anopheles mosquitoes, and other tools such as the Suna trap, sticky resting boxes, baited traps, and human-landing catches require better standardization. Swarm capture 
is a powerful approach but requires great expertise, and this technique is not possible in all locations (Bimbilé Somda et al. 2018). Better understanding of the cues which attract male mosquitoes is leading to traps with improved efficiency, e.g. the SoundGAT (Johnson et al. 2018). In Singapore, mosquito surveillance is achieved using a network or more than 30000 GAT traps monitored weekly (N. Lee Ching, personal communication). Emerging technology for automated passive mosquito surveillance shows great promise; in theory, a network of intelligent traps could automatically identify in real time the species, sex, size, and marker status of insects entering or passing close by (FAO/IAEA 2019a).

\section{PILOT TRIALS AGAINST MOSQUITO VECTORS}

In this new era of interest in applying the SIT against mosquito vectors, until now the pilot trials have been on a small scale, usually focussed on isolated villages or islands. It is perhaps no coincidence that the first projects to reach pilot-scale demonstrations of the SIT are to control Aedine mosquitoes, given their relative amenability to massrearing and sex separation. These small-scale trials are sufficient to demonstrate an impact on some entomological indicators, usually the number of eggs collected per ovitrap, egg-hatch rate, and adult-catch rate. These indicators suggest success, but for the technique to be taken up by abatement districts, governments or charities for implementation on an operational scale, evidence of epidemiological impact of the SIT (reduction of disease incidence) as part of integrated management schemes will be required, involving much larger area-wide trials. Transmission of disease by mosquitoes occurs not just in the home, but also in schools and workplaces, and therefore, unless a community is very isolated with little human movement outside a given area, it will be a challenge to demonstrate disruption of transmission or case reduction. Moreover, in some circumstances, female Aedes appear to disperse much farther than males (up to $800 \mathrm{~m}$ ) (Honório et al. 2003); this will make demonstration of efficacy by current randomized cluster trials very challenging. Current equipment and techniques, in particular sex separation and release methods, will need to be improved dramatically, particularly against Anophelines, before such large-scale trials are possible. Through small-scale pilot trials, many lessons are being learned, which will inform the development of larger projects, e.g. the significance of Ae. albopictus immigration from neighbouring vegetation into urban or semi-urban areas targeted with the SIT, and the requirement for reduction of target populations using conventional methods or IVM prior to, and in conjunction with, applying the SIT.

\subsection{Aedes albopictus in Italy}

Feasibility studies on using the SIT to target invasive Ae. albopictus mosquito populations were started in northern Italy in 2000 (Bellini et al. 2007). The studies included several releases of irradiated males; promising levels of induced sterility were achieved. Where release ratios were high enough, population reduction occurred (Bellini et al. 2013b).

Between 2008 and 2012, six pilot studies of sterile Ae. albopictus male releases were made to test the efficacy of the SIT approach to suppress mosquito populations. 
The release sites were selected as being representative of urban conditions, small enough (10-17 ha) to achieve the required release ratio given the level of sterile-male output that was possible in the Bologna mosquito production unit, and well-isolated from other urban areas. The dynamics of the mosquito populations were monitored weekly in the release and control areas, using standard ovitraps. Eggs collected from the traps were counted under a stereomicroscope and hatched using standard procedures to assess fertility and, conversely, induced sterility (Bellini et al. 2007). Sterile males, released at the rate of 900-1500 males/ha/week, induced sterility levels between 15 and $70 \%$ of the background fertility of the local population. Where induced sterility reached $70 \%$, a similar reduction was found in egg numbers collected by ovitraps. Therefore, inducing sterility levels of $>80 \%$ in the native Ae. albopictus females for an entire season was expected to be sufficient to suppress effectively the mosquito population.

A recent meta-analysis of these trials (R. Bellini, personal communication) found that the released males demonstrated a mean competitiveness value of 0.188 ( $\mathrm{SD} \pm 0.33$ ). This competitiveness (measured as the Capacity to Induce Sterility or CIS index) was highly variable between pilot trials despite very similar environmental conditions being experienced among the sites and similar sterile-male release methods being used in all studies. A strong temporal variability was observed, with lower values found at the beginning and at the end of the summer season (when the wild population density is usually lower and therefore the male sterile:wild ratio is higher) (Albieri et al. 2010; Carrieri et al. 2011). The strong negative correlation between the sterile:wild ratios and the competitiveness values demonstrated in this study was also observed in previous trials conducted under semi-field and field conditions using irradiated and transgenic sterile males (Harris et al. 2011; Damiens et al. 2016). In practical terms, an optimal ratio must be used in SIT operations to maximize costeffectiveness; increasing the release ratio will not result in a proportional increase in induced sterility.

\subsection{Aedes albopictus in Mauritius}

As part of its Operational Plan for Prevention and Control of Chikungunya and Dengue, the Ministry of Health and Quality of Life in Mauritius is evaluating integrating the SIT to control Ae. albopictus populations; the objectives are to prevent outbreaks and the re-establishment of arboviruses in an island benefitting from large numbers of international visitors (Beesoon et al. 2008; Ramchurn et al. 2009). Several characteristics of Mauritius make it a very suitable country in which to test the feasibility of applying the SIT. Identifying potentially suitable sites for pilot-trial releases, and corresponding control areas, is straightforward due to the largely agricultural nature of the island of Mauritius. Small discrete villages exist, often located on the coast or surrounded by sugar cane fields providing geographical isolation. In some villages Ae. albopictus is the only Aedine mosquito present or at least the dominant species. Two suitable villages were selected for the first pilot trial: Pointe des Lascars $\left(0.3 \mathrm{~km}^{2}\right.$, consisting of 203 houses and 800 inhabitants $)$ and Panchvati $\left(0.03 \mathrm{~km}^{2}\right.$, consisting of 67 houses and 270 inhabitants) (Iyaloo et al. 2014). The villages, located $1.6 \mathrm{~km}$ from each other, are well-matched in terms of the human 
inhabitants, natural geography, infrastructure, and mosquito populations. Routine monitoring and mark-release-recapture experiments showed that the majority of ovitraps are positive for eggs throughout the year, with peaks in December-March and troughs in July-September (Iyaloo et al. 2019).

To determine survival and dispersal of sterile males in this ecological setting, three mark-release-recapture (MRR) experiments (Itô et al., this volume; Vreysen, this volume) were performed in Pointe des Lascars (Iyaloo et al. 2019). A release rate of $6000 \mathrm{males} / \mathrm{ha}$ was applied during the winter season, and at least twice that number in the summer. When assessed in a laboratory, marking males (with a fluorescent dust) did not affect their performance (Dowell et al., this volume). After applying a dose of 40 Gy with a gamma irradiator, tests showed that: (1) dispersal was not affected by irradiation, and (2) irradiated males survived up to 12 days; on average, unirradiated males survived 4 days longer (Bakri et al., this volume).

In parallel with baseline mosquito surveillance (using ovitraps and BG-Sentinel traps), a colony of mosquitoes from the pilot villages was established in a climatecontrolled insectary at the Vector Biology and Control Division. For larval diets, two animal feeds were shown to be suitable and cost-effective (USD 1/kg); they are manufactured locally (important for an island nation) (Iyaloo and Facknath 2017). Mosquitoes were reared using the tray and rack system described by Balestrino et al. (2014b), and large commercially available adult cages. Sex separation of release cohorts, done on the basis of pupal size (using graded sieves), achieved a maximum of $4 \%$ female contamination. Adult females were further removed from the release cages with an aspirator. Batches of 2000 male pupae were irradiated at 30-40 hours old, as was done for the MRR trials, and allowed to emerge into small adult cages containing a sugar meal. Adults were transported to the field in the small cages for release 3 days after emergence.

Prior to the pilot trial, staff of the Ministry of Health and Quality of Life went from house to house (in the release and control sites) inviting people to attend sensitization meetings, held in the village hall, during which the project was explained, and also a cage of male mosquitoes was used to demonstrate that they do not bite. During the trial, field officers working in the pilot sites were mobilized to talk to the public at least once per week to hear and address any concerns (D. P. Ilyaloo, personal communication).

In the first mosquito SIT trial in Mauritius, IVM was applied during the first two months of the project, applying larval-source reduction, weekly Bacillus thuringiensis israelensis (Bti) applications, and biweekly pyrethroid fogging alongside sterile-male releases (Mangan and Bouyer, this volume). Each week, for 9 months, 60000 sterile males were released, equally distributed among 10 release sites in Panchvati for the first 6 months and 20 sites for the remainder of the trial period. Ovitrap surveillance within (and in a 150-m radius around) Panchvati and within Pointe des Lascars, and biweekly 24-h collections using 8 BG-Sentinel traps in both villages, showed a significant decrease in oviposition and the adult population as a result of the IVM treatments. This was reversed in the control village when vector treatments were halted, but not in the village where sterile-male releases alone continued. Egg fertility remained stable throughout the trial period in Pointe des Lascars, but was significantly lower in Panchvati during the period of releases (except for a period in the immediate 
aftermath of tropical cyclone Berguitta). During the period of sterile-male releases, induced sterility reached more than $30 \%$, the number of eggs collected per ovitrap dropped by more than $50 \%$, and adult catch was less than one half that in the control village (D. P. Ilyaloo, personal communication). Ovitraps in the area surrounding Panchvati tended to collect more eggs than within the village, suggesting that immigration of fertile females into the treatment area was acting against the population suppression efforts.

As in the Italian SIT pilot studies, releases were more effective the lower the initial population density at the target site; low densities enabled a higher release ratio given the rearing resources available, and possibly also a greater competitive advantage for the sterile insects. Permitting sterile males to mature, and take a sugar meal before release, improved mating competitiveness. In the ecological setting of Mauritius, initiating the targeted release of sterile males in the winter season is likely to be most effective in reducing the peak summer adult population, but sustained releases over several years would be required to sustainably reduce, or even locally eliminate, populations due to the stockpile of eggs of the wild population; these eggs are laid each season and hatch when the rains arrive.

\subsection{Other Pilot Trials against Mosquitoes}

Many other pilot trials are ongoing or have been completed in various countries, and many more are in the planning stages (Table 1), indicating the current high level of interest and ongoing activities to develop and integrate the SIT and/or IIT, as well as transgenic approaches, against disease-transmitting mosquitoes.

\section{LOOKING TO THE FUTURE}

The major elements required to apply the SIT against major mosquito vectors of disease are in place. The remaining challenges, that need to be overcome before it can be applied operationally on a large scale, are just technical improvements and upscaling, particularly in terms of sex separation, methods of releasing males, and accurate monitoring of male populations.

The technology for mass-rearing mosquitoes is well advanced (section 2.1.1.; Parker, Mamai et al., this volume): mass-production of larvae in racks of large trays (Balestrino et al. 2014a), separation of larvae from pupae (Balestrino et al. 2011), and housing and feeding of adults for egg production and storage (Balestrino et al. 2014b; Maïga et al. 2017). Methodological improvements are ongoing to increase efficiency and decrease costs (directly and through automation to reduce the labour required). For example, the reuse or recycling of larval-rearing water (Mamai et al. 2017) is a significant factor in the feasibility of mass-rearing mosquitoes in water-limited environments. The costs of mass-rearing equipment are being reduced (Maïga et al. 2019) and adult and larval diets improved (Bimbilé Somda et al. 2017, 2019). Currently, two issues are still being addressed (to enable mass-deployment) -- the need for a sex-sorting system (section 4.1.) that is efficient on a large scale (particularly for Anophelines), and the development of technologies to release mosquitoes aerially using UAVs (Dowell et al., this volume). 
Table 1. SIT, IIT, and transgenic pilot trials against mosquitoes

\begin{tabular}{|c|c|c|c|c|}
\hline $\begin{array}{c}\text { Type of } \\
\text { approach used }\end{array}$ & $\begin{array}{l}\text { Mosquito } \\
\text { species }\end{array}$ & Location & Trial staus & Reference \\
\hline \multirow{3}{*}{ SIT pilots $^{1}$} & $\begin{array}{l}\text { Aedes } \\
\text { aegypti }\end{array}$ & Mexico & Concluded & FAO/IAEA 2018c \\
\hline & & Italy, Mauritius & Concluded & $\begin{array}{l}\text { Bellini 2013b; } \\
\text { D. P. Iyaloo, personal } \\
\text { communication }\end{array}$ \\
\hline & $\begin{array}{l}\text { Aedes } \\
\text { albopictus }\end{array}$ & $\begin{array}{l}\text { La Réunion } \\
\text { (France), Germany, } \\
\text { Greece, Italy, } \\
\text { Montenegro, Spain }\end{array}$ & Ongoing & $\begin{array}{l}\text { TIS 2019; } \\
\text { R. Bellini, personal } \\
\text { communication; } \\
\text { I. Pla Mora, personal } \\
\text { communication }\end{array}$ \\
\hline \multirow{3}{*}{ SIT/IIT pilots } & \multirow[t]{2}{*}{$\begin{array}{l}\text { Aedes } \\
\text { aegypti }\end{array}$} & Thailand & Concluded & $\begin{array}{l}\text { Kittayapong et al. } \\
\text { 2018; Kittayapong } \\
2021\end{array}$ \\
\hline & & Singapore & Ongoing & FAO/IAEA $2018 \mathrm{c}$ \\
\hline & $\begin{array}{l}\text { Aedes } \\
\text { albopictus }\end{array}$ & China & Concluded & $\begin{array}{l}\text { Jozuka 2016; } \\
\text { Zheng et al. 2019; } \\
\text { Baton et al. 2021 }\end{array}$ \\
\hline \multirow{6}{*}{$\begin{array}{l}\text { IIT pilots for } \\
\text { suppression - } \\
\text { releasing only } \\
\text { Wolbachia- } \\
\text { infected males }\end{array}$} & \multirow{2}{*}{$\begin{array}{l}\text { Aedes } \\
\text { aegypti }\end{array}$} & $\begin{array}{l}\text { Debug-Verily in } \\
\text { Australia and USA }\end{array}$ & Not clear & $\begin{array}{l}\text { Haridy 2017; } \\
\text { Debug-Verily } 2019\end{array}$ \\
\hline & & $\begin{array}{l}\text { Singapore (Project } \\
\text { Wolbachia) }\end{array}$ & Ongoing & $\begin{array}{l}\text { Co 2019; NEA 2019a, } \\
\text { b; Liew et al. } 2021\end{array}$ \\
\hline & \multirow{2}{*}{$\begin{array}{l}\text { Aedes } \\
\text { albopictus }\end{array}$} & Florida (USA) & Concluded & Mains et al. 2016, 2019 \\
\hline & & $\begin{array}{l}\text { MosquitoMate in } \\
\text { USA }\end{array}$ & Ongoing & MosquitoMate 2019 \\
\hline & \multirow{2}{*}{$\begin{array}{l}\text { Aedes } \\
\text { polynesiensis }\end{array}$} & $\begin{array}{l}\text { Raiatea (French } \\
\text { Polynesia) }\end{array}$ & Concluded & O’Connor et al. 2012 \\
\hline & & $\begin{array}{l}\text { Tetiaroa (French } \\
\text { Polynesia) }\end{array}$ & Concluded & $\begin{array}{l}\text { Bown 2019; Strugarek } \\
\text { et al. } 2019\end{array}$ \\
\hline $\begin{array}{l}\text { IIT pilots for } \\
\text { population } \\
\text { replacement -- } \\
\text { releasing also } \\
\text { Wolbachia- } \\
\text { infected females }\end{array}$ & $\begin{array}{l}\text { Aedes } \\
\text { aegypti }\end{array}$ & $\begin{array}{l}\text { World Mosquito } \\
\text { Programme -- } \\
\text { Australia, Brazil, } \\
\text { Colombia, India, } \\
\text { Indonesia, Mexico, } \\
\text { Pacific Islands, Sri } \\
\text { Lanka, Vietnam }\end{array}$ & Ongoing & $\begin{array}{l}\text { Flores and O’Neill } \\
\text { 2018; WMP } 2019\end{array}$ \\
\hline \multirow{2}{*}{$\begin{array}{l}\text { Transgenic } \\
\text { mosquito pilots }\end{array}$} & \multirow{2}{*}{$\begin{array}{l}\text { Aedes } \\
\text { aegypti }\end{array}$} & $\begin{array}{l}\text { Oxitec -- Brazil, } \\
\text { Cayman Islands, } \\
\text { Panama }\end{array}$ & Concluded & $\begin{array}{l}\text { Harris et al. 2011; } \\
\text { Carvalho et al. 2015; } \\
\text { Gorman et al. } 2015\end{array}$ \\
\hline & & $\begin{array}{l}\text { Oxitec-Brazil, } \\
\text { Panama, USA }\end{array}$ & Ongoing & Oxitec 2019 \\
\hline
\end{tabular}

${ }^{1}$ In addition, pilot SIT projects will begin in 2019 against Ae. aegypti in Brazil, Cuba, Indonesia, Malaysia, the Philippines, and the USA (Florida), and against An. arabiensis in South Africa. 
The process of handling and transporting sterile males from a mass-rearing facility to release sites could be streamlined and standardized so as to minimize the impact on male survival and performance, and to enable upscaling the release technology. For example, handling could be minimized by loading sterilized male pupae into emergence cages; after emergence the adults can be fed a sugar meal and then chilled and concentrated into transport cassettes (with the emergence cages removed) which are loaded into ground- or aerial-release vehicles.

Aerial release of mosquitoes will enable the SIT to be applied in a wider range of circumstances, including situations where access by road is difficult or the labour costs of the fine-scale release of sterile males are prohibitive. A releasing system on a UAV was tested successfully in Brazil (FAO/IAEA 2016a, 2018a). The survival of aerially released Ae. aegypti males was not significantly different from that of males released on the ground, suggesting that the impact of the aerial release system on insect quality was minimal. Moreover, at a sterile:wild ratio of only $3: 1$, the induced egg sterility reached $50 \%$ in the release area; this is very promising (J. Bouyer, unpublished data). However, further fine-tuning of the technology and approach, and the likely involvement of the private sector, will be needed to produce reliable industrial versions of the release system, and enable it to be used, eventually also commercially, in operational vector-control programmes (Dowell et al., this volume).

The priority for the operational development of the SIT against mosquitoes is to upscale field trials, demonstrate impact on mosquito populations, and ultimately prevent cases of disease. The FAO/IAEA and WHO are presently collaborating to develop common operational guidance on applying the SIT to control mosquito-borne diseases, and to offer technical guidance to countries planning to integrate the SIT into their integrated management strategies. This guidance will cover all practical aspects relating to the trial and early application of the technology, e.g. production, transport, and release of sterile males, associated quality-control parameters, clearly defined entomological and epidemiological indicators of efficacy in large-scale entomological trials, and frameworks to assess risk, safety implications, and cost-effectiveness. Guidance will follow a phase-conditional approach, and will include strategies for community and media engagement, disease surveillance under large-scale deployment, monitoring, and evaluation of success, and a description of legal frameworks for registration and regulation related to operational SIT programmes (FAO/IAEA 2019b; Bouyer et al. 2020; WHO/IAEA 2020).

\subsection{Need for Scalable and Effective Sex Separation}

Although perfect sex separation may not be an absolute requirement for the efficacy of the SIT, in the case of mosquitoes (where females are the vectors of disease) the tolerance for even low-level female contamination in the release population is very low (section 2.1.1.). Options for improved sex-sorting that are currently available include using classical genetics to produce a genetic sexing strain (GSS), such as the dieldrin-sexing strain in An. arabiensis (Yamada et al. 2012). This system was very effective in sorting males (resistant to rearing solutions containing 2 to 4 ppm dieldrin, unlike females) but presented two drawbacks: a reduced egg fertility and thus low strain productivity, and the presence of dieldrin residues on the released males and the 
associated risk of bioaccumulation in the environment (Yamada et al. 2015). Another option is to exploit the fact that only female mosquitoes feed on blood, i.e. add a toxicant to the blood meal (Yamada et al. 2013); though effective on a small scale, this may not be feasible for mass-rearing, particularly where a $100 \%$ male-release population is absolutely required.

Significant effort is being expended to develop new methods of sex separation (Papathanos et al. 2009, 2018; Bourtzis and Tu 2018). Sorting systems have been developed in Aedes species based on their sexual dimorphism, attempting to improve on the Fay-Morlan separator (Fay and Morlan 1959; Focks 1980) for larger-scale rearing. They enable mature pupae to be separated automatically on the basis of sex (Fig. 3) (Araújo et al. 2018; Bellini et al. 2018; Zacarés et al. 2018); at small-scale rearing up to $99 \%$ of males are recovered, and contamination by females is lower than $0.1 \%$. An automated sieving system has been developed to separate Ae. aegypti pupae on the basis of smaller (male) pupae being able to pass up through openings in a submerged surface while larger (female) pupae are trapped below (Justia Patents 2017; Debug-Verily 2019). Another automatic pupae sex-separator, that can sort up to 150000 pupae per hour with a female contamination rate below $0.3 \%$, has been developed for Ae. albopictus by Wolbaki Biotech in China (Baton et al. 2021).

The size difference between Anopheles male and female pupae is less pronounced, and they are less robust and more easily damaged, making such sorting impossible (Mashatola et al. 2018). However, a similar system is under development to sort mature pupae of a sexing strain expressing sexual dimorphism in eye colour (K. Bourtzis, personal communication), which may be more amenable for Anopheles sex sorting, and the two systems may be combined to further improve the purity of the male-only release population. Nevertheless, these sexing systems are based on the sorting of pupae, making it necessary to produce female larvae; if females could be removed earlier in development, production costs could potentially be reduced by one half. Also, these methods are labour-intensive; it is very challenging to remove every female without losing a large proportion of males, further escalating the rearing costs.

Mechanical systems are unlikely ever to separate the sexes with $100 \%$ efficiency, and certainly not on a large scale; a few females will always be released. There is then a danger of "population replacement" when using only the IIT, but when the IIT and radiation-sterilization are combined, this cannot happen - any released females are sterile (and cannot transmit disease because of the Wolbachia infection) (section 4.2.).

A more efficient method of separation will be required before the SIT can be applied to mosquitoes on an operational scale, most likely relying on a GSS. A GSS in An. albimanus was produced in the 1970s for the SIT project in El Salvador but was lost after the trial was terminated (Dame et al. 2009). Producing GSSs by classical genetics is lengthy and labour-intensive because it relies on mutagenizing and screening large numbers of individual families (due to the low probability of mutagenesis producing the desired linkage event) (Lebon et al. 2018; Ndo et al. 2018). In Aedes, species sex is determined by a male-determining factor located on a small, non-recombining $\mathrm{M}$ locus on chromosome 1 and not on a heteromorphic sex chromosome (Hall et al. 2015), making it more unlikely and therefore more laborious to achieve translocation of the selectable marker to the sex-determining chromosome (Papathanos et al. 2018). 

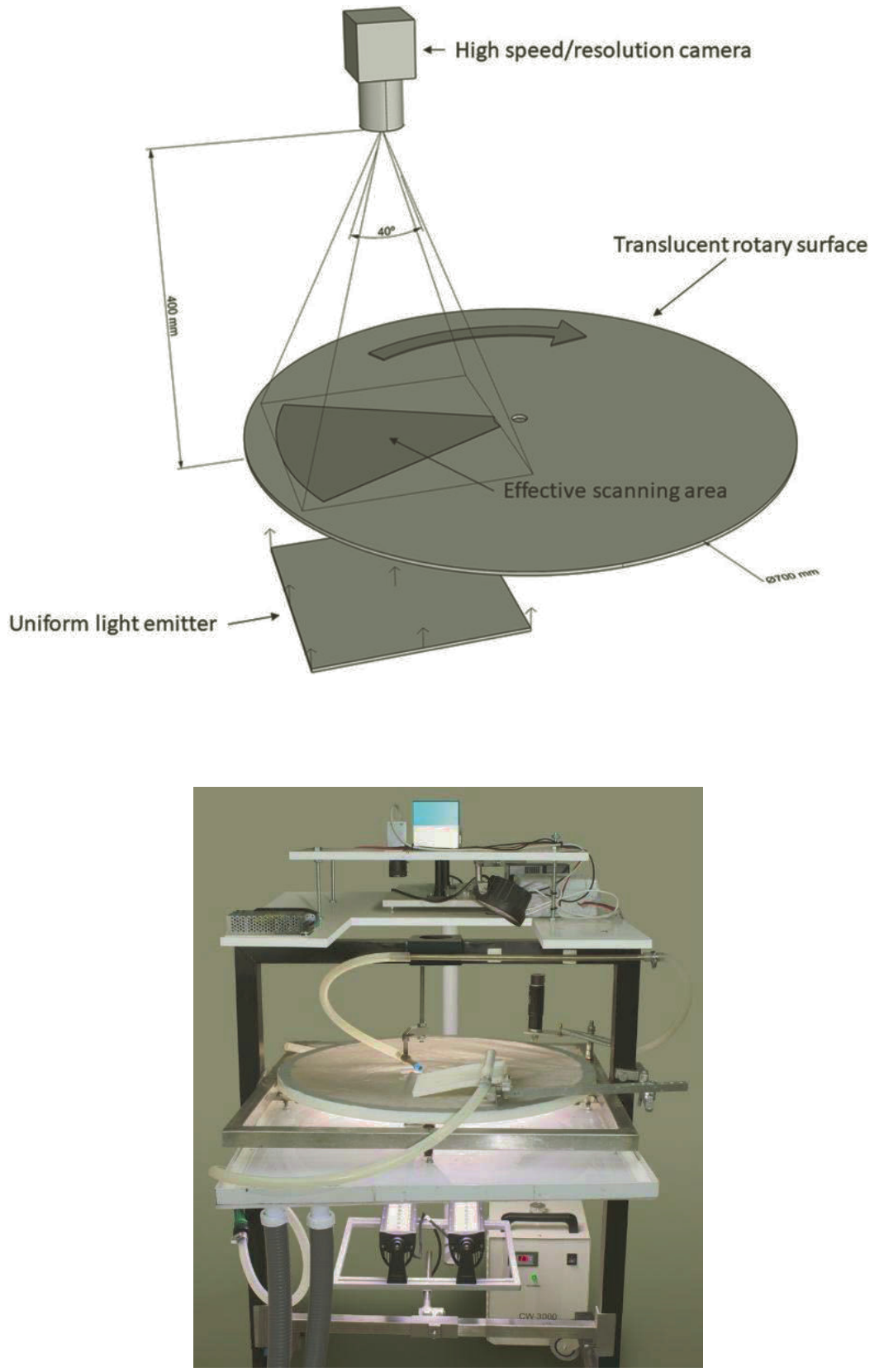

Figure 3. Upper drawing: Camera set-up for sorting male and female Aedes pupae based on size dimorphism. (Drawing from Zacarés et al. 2018, reproduced with permission.) Lower photo: Prototype laser sex-sorting machine (Bourtzis 2019). 
However, a promising approach, using modern molecular techniques, is to identify temperature-sensitive lethal ( $t s l)$ genes, and to link them to sex-specific genes to enable the removal of females as first-instar larvae or even as embryos through classical genetics (as is done for C. capitata (Franz et al., this volume)). Modern molecular tools that can be used to produce transgenic as well as non-transgenic sexing strains have been widely reviewed (Catteruccia et al. 2009; Bernardini et al. 2018; Häcker and Schetelig 2018; Lutrat et al. 2019; Häcker et al., this volume).

An alternative approach could be to feed double-stranded RNAs (dsRNAs) to mosquito larvae (Whyard et al. 2015). By targeting both the testis genes and a female sex determination gene (doublesex) to induce RNA interference (RNAi), female development can be successfully inhibited (Häcker et al., this volume). To be effective, the dsRNA must be available constantly during relevant developmental stages to guarantee the silencing effect, though the cost of producing these dsRNAs may be reduced through the culture of transformed bacteria or yeast.

Flow cytometry machines (COPAS ${ }^{\circ}$, Union Biometrica) could be used for highthroughput separation of males from females based on the sex-specific expression of a fluorescence marker, e.g. sperm-specific expression in the testes (Marois et al. 2012). This approach is still being upscaled for mass-rearing, but relies on the use of transgenic strains, whose "open release" is limited or prohibited in some countries. Irradiating these transgenic strains to sterilize them before release would enable them to benefit from a non-GMO status in European countries, where only fertile material is considered as an organism. Under the Nagoya protocol (CBD 2014), even the release of sterile GMOs is tightly controlled, though their release is authorized in Europe (Lutrat et al. 2019). Using approaches such as CRISPR/Cas engineering, targeted mutagenesis through gene editing could be used to create GSSs which do not contain exogenous DNA and thus are not classed as transgenics, facilitating their acceptance for release (Kandul et al. 2019; Häcker et al., this volume).

\subsection{Combined SIT/IIT Approach to Control Aedes}

In parallel with the increased interest in applying the SIT against mosquito vectors of disease, there has also been much interest in developing and applying the incompatible insect technique (IIT), and exploring its potential through Wolbachia-based approaches to enhance the SIT (Zabalou et al. 2004; Moretti et al. 2018; Baton et al. 2021). The IIT relies on cytoplasmic incompatibility (CI) between released males (which carry a Wolbachia infection) and wild females (with no infection, or a different and incompatible infection), thus resulting in sterile matings. Moreover, introduced Wolbachia infection makes females refractory to arboviral transmission. Starting in 2011 in Australia, field trials releasing Wolbachia-infected Ae. aegypti females and males have been successful at population replacement (Hoffmann et al. 2011). However, such self-sustaining releases (Alphey 2014) have the intent to establish permanently the Wolbachia strain in the target population, a process (that unlike the SIT) is irreversible and leaves an "ecological footprint". On the other hand, releasing only Wolbachia-infected males is self-limiting, and results in population suppression similar to the SIT, without any permanent changes in the target population (Bourtzis et 
al. 2014, 2016); it is essential that only males are released, otherwise population replacement can take place.

Until effective genetic sexing strains become available for large-scale SIT application, combining the SIT with the IIT provides important benefits for an operational scale (Arunachalam and Curtis 1985; Bourtzis and Robinson 2006; Brelsfoard et al. 2009). A strain of Ae. albopictus, carrying three strains of Wolbachia ( $w$ AlbA, $w \mathrm{AlbB}$, and $w \mathrm{PiP}$ ), has been shown to express strong cytoplasmic incompatibility and good mating competitiveness in semi-field tests after irradiation at 28 Gy (a fully sterilizing dose for females) (Zhang et al. 2016). Thus, due to the sterility given to males by cytoplasmic incompatibility, a lower irradiation dose can be used to sterilize females, minimizing the impact on male performance (Zhang et al. $2015 \mathrm{a}, \mathrm{b})$. At the same time, including the IIT precludes potential disease transmission by any inadvertently released females (which make up at least $1 \%$ of the release population in upscaled SIT releases using current sexing systems). On the other hand, simultaneous sterilization guarantees that such inadvertently released females cannot reproduce; this will prevent Wolbachia from becoming established in the target population (resulting in the loss of cytoplasmic incompatibility and creating resistance to the IIT approach) (Lees et al. 2015; Bourtzis et al. 2016; NEA 2018). However, in Europe, this approach is at present limited by the absence of regulation.

An early pilot trial of the combined IIT and SIT approach against Ae. aegypti, conducted in a village in Chachoengsao Province, eastern Thailand, showed a significant reduction in hatch rate, and a lower total adult catch, during 6 months of weekly releases compared with the control area (Kittayapong et al. 2018; Kittayapong 2021). Released males were infected with Wolbachia collected from a local Ae. albopictus strain, irradiated as pupae with 70 Gy using gamma rays, and confirmed to be sterile by crossing a sample of each release cohort with non-irradiated Wolbachiainfected females to score fertility. In a small-cage laboratory test, released males were shown to be equally competitive to non-irradiated Wolbachia-infected males. A total of 10 000-25 000 one-day-old males was released (100-200 per household per week) for 6 months from delivery containers in which pupae had emerged and been provided with a sugar feed. Local support was garnered in the pilot site through strong community engagement and public awareness activities, even involving householders in the releases (Dyck, Regidor Fernández et al., this volume). Adult abundance was monitored monthly using sticky traps, and collections were made with portable vacuum aspirators. Ovitraps were collected weekly to monitor hatch rate (Vreysen, this volume).

\subsection{New Opportunities in the Integrated Management of Mosquito-Borne Diseases Offered by the SIT}

The SIT technology is ready to be applied in pilot trials and small-scale population suppression programmes for integrated mosquito control (FAO/IAEA 2015; Lees et al. 2015). In the efforts to control malaria, the SIT may, under specific conditions (particularly against exophilic species such as An. arabiensis where conventional control by insecticide-treated nets and indoor residual sprays is less effective), become a powerful adjunct to other technologies. This would be in accordance with the World 
Health Organization's Roll Back Malaria strategy (Nabarro 1999), and more recently the WHO's Global Vector Control Response 2017-2030 (WHO 2017a), which promote integrated vector management rather than reliance on any single approach to control malaria. Given the advanced state of development of the SIT against Ae. aegypti, and in response to the widespread epidemic of the Zika disease in 2015-2016, FAO/IAEA proposed the technology as part of an integrated Zika management strategy (FAO/IAEA 2016b).

Advances in molecular biology and biotechnology have provided several potential genetic methods to manage mosquito populations, offering different opportunities and challenges relative to the SIT (Catteruccia et al. 2009; Alphey 2014; Bouyer and Marois 2018; Flores and O’Neill 2018; Häcker et al., this volume). Also, it has been proposed that the SIT can be boosted by treating the males with biocides, like juvenile hormone analogues or specific biopesticides like densovirus, before release (Bouyer and Lefrançois 2014; Bouyer et al. 2016). During mating, or even mating attempts, sterile males could transmit these biocides to females, which would in turn transfer them to oviposition sites. As an example, treating sterile male Ae. albopictus with pyriproxyfen may enable the number of males released into a given area to be reduced by more than ten-fold, and achieve a more reliable and sustainable impact on dengue transmission (Pleydell and Bouyer 2019). The principle has been tested with success on a very small scale against Ae. aegypti in Kentucky (Mains et al. 2015), and further trials are planned in Spain and France.

The fact that the SIT is self-limiting, unlike population replacement based on Wolbachia or gene drive of transgenic traits, is one of its advantages. However, this is also a drawback -- releases must be sustained over time, involving permanent costs to prevent disease transmission in a given area. Other advantages of the SIT are that it is species-specific, and has no regulatory requirements (unlike most other proposed genetic control methods that require approval for releases) (Reeves et al. 2012; Hendrichs and Robinson, this volume). Also, it has a positive public perception and no restrictions on intellectual property rights -- each country is able to use its own local mosquito strains to apply the technology.

Finally, random mutations, chromosome breakages, and gross gonad damage caused by radiation eliminates the risk of resistance development - unlike insecticides and potentially other genetic control methods (Alphey et al. 2011; Eckermann et al. 2014; Handler 2016; The Economist 2017; Häcker et al., this volume; Hendrichs and Robinson, this volume; Whitten and Mahon, this volume). Contrary to a wrong perception that this sterilization process is necessarily associated with a loss of competitiveness of the sterile males, field trials of alternative technologies, especially RIDL, demonstrated that competitiveness of transgenic males can be much lower than what has been observed with irradiated males (Benedict and Robinson 2003; Facchinelli et al. 2013). This is related primarily to the fact that in mosquitoes the SIT is based on local strains that are well-adapted to local environments, whereas transgenic strains have often been colonized for decades.

In other insects, e.g. tsetse flies, it has been demonstrated that a loss of competitiveness is usually the result of a combination of factors such as mass-rearing, handling, chilling, and transport rather than irradiation itself (Diallo et al. 2018). This will affect equally all genetic control methods based on the mass-release of males. 
Optimizing the rearing conditions is critical to minimize the impact of laboratory adaptation and other manipulations on adult male quality (Bargielowski et al. 2011).

An understanding of the reasons for a negative correlation between competitiveness and the sterile:wild male ratio (seen in the SIT trials in Italy) will be instrumental for planning future mosquito control programmes that have an SIT component. One of the major hypotheses for this phenomenon is that a proportion of the female population might be protected from sterile males regardless of the release ratio because they are located in cryptic habitats, and it is difficult for the released sterile males to access these. This illustrates the importance of released sterile males matching the behaviour of wild males by, for example, aggregating in the same microhabitats (Vreysen at al. 2011). Also, there probably is an optimum ratio of sterile to wild males beyond which no increase in the ratio results in a higher induced sterility. It is important to identify this optimal ratio because accurate estimates of sterile-male release densities would maximize the cost-efficiency of SIT projects.

Another reason might be immigration of fertile females into the target area from neighbouring sites where sterile males are not released (the females have a much higher dispersal capacity than males) (Honório et al. 2003). Therefore, a tailored distribution of sterile males in the target area and surroundings is needed so as to achieve an adequate overflooding ratio even where wild populations are at high densities, especially when releasing into urban settings characterized by many favourable cryptic micro-habitats. Hot spots with a high mosquito population density should be identified and targeted appropriately, although this is challenging with existing monitoring tools and is not currently achievable on a large scale.

The SIT is not a stand-alone technology, and needs to be applied in combination with other pest control methods as part of an area-wide integrated pest management (AW-IPM) approach (Hendrichs, Vreysen et al., this volume; Klassen and Vreysen, this volume; Mangan and Bouyer, this volume). In particular, population reduction achieved through public participation in larval-site reduction will usually be a prerequisite, and will require that there is a strong stakeholder engagement in all projects (Dyck, Regidor Fernández et al., this volume).

\section{CONCLUSIONS}

At present, many SIT pilot trials against mosquitoes are ongoing or in preparation (Table 1). These field trials will create important knowledge needed for future upscaling of the technology. The most illustrative recent example is the SIT/IIT pilot trial in China that successfully suppressed, and nearly eliminated, two field populations of Ae. albopictus over a two-year period. Millions of sterile males were released, with prior pupal irradiation. Community support for the SIT/IIT approach strongly increased following mosquito releases, as nuisance-biting decreased. This successful field trial has fully demonstrated the feasibility of area-wide application of SIT/IIT for mosquito vector control (Zheng et al. 2019).

Area-wide releases, focused on urban/suburban settings and touristic sites, appear particularly promising in terms of sustainable and cost-effective IVM with an SIT component (eventually provided commercially by the private sector), as they can protect many people concentrated in relatively small areas. 
The potential impact of the successful control of mosquito vectors, through the combined use of the SIT and other control methods, can be estimated based on previous successful programmes. When the Panama Canal was constructed, mosquito control during a period of $5 \mathrm{y}$ had a significant economic and social impact on the region - eliminating yellow fever and drastically reducing malaria transmission, enabling the Panama Canal to be completed, and promoting the development of the entire area (RES 2014). In Brazil in the 1930s and 1940s, similar benefits were seen when a broad range of strategies was used to eradicate the invasive An. gambiae (Hendrichs, Enkerlin et al., this volume). In each of these cases, the community saw these programmes as drastic, due to, for example, the use of military force to achieve the goals, but the resulting impact on morbidity and development overcame the negative reactions (Severo 1956; Ockenhouse et al. 2005; Griffing et al. 2015).

Between 1990 and 2010, the global burden from neglected tropical diseases declined by $27 \%$; however, this reduction occurred mostly in upper-middle-income countries. If the latest WHO targets are met between 2010 and 2020, a 55\% reduction in the global burden in each country would be achieved, with an even greater reduction in low- and lower-middle-income countries (Stolk et al. 2016). It is expected that including the SIT among methods used to control mosquitoes will contribute to achieving the WHO goal, and result in increased human well-being, reduced deaths from vector-borne diseases, and increased development in deeply affected areas.

\section{REFERENCES}

Ageep, T. B., D. Damiens, B. Alsharif, A. Ahmed, E. H. O. Salih, F. T. A. Ahmed, A. Diabaté, R. S. Lees, J. R. L. Gilles, and B. B. El Sayed. 2014. Participation of irradiated Anopheles arabiensis males in swarms following field release in Sudan. Malaria Journal 13: 484. https://doi.org/10.1186/1475-2875-13-484

Akram, M., and M. Aslamkhan. 1975. Production of dominant lethal mutations by gamma irradiation in the malaria mosquito, Anopheles stephensi. Pakistan Journal of Zoology 7: 177-184.

Albieri, A., M. Carrieri, P. Angelini, F. Baldacchini, C. Venturelli, S. Mascali Zeo, and R. Bellini. 2010. Quantitative monitoring of Aedes albopictus in Emilia-Romagna, Northern Italy: cluster investigation and geostatistical analysis. Bulletin of Insectology 63(2): 209-216. http://www.bulletinofinsectology.org/pdfarticles/vol63-2010-209-216albieri.pdf

Alfaro-Murillo, J.A., Parpia, A.S., Fitzpatrick, M.C., Tamagnan, J.A., Medlock, J., Ndeffo-Mbah, M.L., D. Fish, M. L. Ávila-Agüero, R. Marín, A. I. Ko, and A. P. Galvani. 2016. A costeffectiveness tool for informing policies on Zika virus control. PLOS Neglected Tropical Diseases 10(5): e0004743. https://doi.org/10.1371/journal.pntd.0004743

Alphey, L. 2014. Genetic control of mosquitoes. Annual Review of Entomology 59: 205-224. https://doi.org/10.1146/annurev-ento-011613-162002

Alphey, N., M. B. Bonsall, and L. Alphey. 2011. Modeling resistance to genetic control of insects. Journal of Theoretical Biology 270: 42-55. https://doi.org/10.1016/j.jtbi.2010.11.016

Araújo, H. R. C. D., D. O. Carvalho, R. S. Ioshino, A. L. Costa-da-Silva, and M. L. Capurro. 2015. Aedes aegypti control strategies in Brazil: incorporation of new technologies to overcome the persistence of dengue epidemics. Insects 6(2): 576-594. https://doi.org/10.3390/insects6020576

Araújo, H. R. C. D., B. B. Kojin, and M. L. Capurro. 2018. Sex determination and Aedes population control. Parasites and Vectors 11(Suppl. 2): 644. https://doi.org/10.1186/s13071-018-3217-6

Arunachalam, N., and C. F. Curtis. 1985. Integration of radiation with cytoplasmic incompatibility for genetic control in the Culex pipiens complex (Diptera: Culicidae). Journal of Medical Entomology 22: 648-653. https://doi.org/10.1093/jmedent/22.6.648

Asante, F. A., and K. Asenso-Okyere. 2003. Economic burden of malaria in Ghana. AFRO, WHO. http://www.intromodeling.com/wpcontent/uploads/2017/05/Economic_Burden_of_Malaria_in_Ghana_Final_Report_Nov03.pdf 
Ashraf, Q. H., A. Lester, and D. N. Weil. 2009. When does improving health raise GDP? NBER Macroeconomics Annual 2008. Volume 23 (April): 157-204. https://www.nber.org/chapters/c7278

Balestrino, F., A. Medici, G. Candini, M. Carrieri, B. Maccagnani, M. Calvitti, S. Maini, and R. Bellini. 2010. Gamma ray dosimetry and mating capacity studies in the laboratory on Aedes albopictus males. J. Medical Entomology 47: 581-591. https://doi.org/10.1093/jmedent/47.4.581

Balestrino, F., J. R. L. Gilles, S. M. Soliban, A. Nirschl, Q. E. Benedict, and M. Q. Benedict. 2011. Mosquito mass rearing technology: a cold-water vortex device for continuous unattended separation of Anopheles arabiensis pupae from larvae. Journal of the American Mosquito Control Association 27(3): 227-236. https://doi.org/10.2987/10-6085.1

Balestrino, F., M. Q. Benedict, and J. R. L. Gilles. 2012. A new larval tray and rack system for improved mosquito mass rearing. J. Med. Ent. 49(3): 595-605. https://doi.org/10.1603/ME11188

Balestrino, F., A. Puggioli, R. Bellini, D. Petric, and J. R. L. Gilles. 2014a. Mass production cage for Aedes albopictus (Diptera: Culicidae). J. Med. Ent. 51: 155-163. https://doi.org/10.1603/ME13130

Balestrino, F., A. Puggioli, J. R. L. Gilles, and R. Bellini. 2014b. Validation of a new larval rearing unit for Aedes albopictus (Diptera: Culicidae) mass rearing. PLOS ONE 9(3): e91914. https://doi.org/10.1371/journal.pone.0091914

Balestrino, F., A. Puggioli, M. Carrieri, J. Bouyer, and R. Bellini. 2017. Quality control methods for Aedes albopictus sterile male production. PLOS Neglected Tropical Diseases 11(9): e0005881. https://doi.org/10.1371/journal.pntd.0005881

Bargielowski, I., D. Nimmo, L. Alphey, and J. C. Koella. 2011. Comparison of life history characteristics of the genetically modified OX513A line and a wild type strain of Aedes aegypti. PLOS ONE 6(6): e20699. https://doi.org/10.1371/journal.pone.0020699

Batista, E. P. A., S. A. Mapua, H. Ngowo, N. S. Matowo, E. F. Melo, K. S. Paixão, A. E. Eiras, and F. O. Okumu. 2019. Videographic analysis of flight behaviours of host-seeking Anopheles arabiensis towards BG-Malaria trap. PLOS ONE 14(7): e0220563. https://doi.org/10.1371/journal.pone.0220563

Baton, L. A., D. Zhang, Y. Li, and Z. Xi. 2021. Combining the incompatible and sterile insect techniques for pest and vector control, pp. 367-404. In J. Hendrichs, R. Pereira and M. J. B. Vreysen (eds.), Areawide integrated pest management. Development and field application. CRC Press, Boca Raton, USA.

Beesoon, S., E. Funkhouser, N. Kotea, A. Spielman, and R. M. Robich. 2008. Chikungunya fever, Mauritius, 2006. Emerg. Infectious Dis. 14(2): 337-338. https://dx.doi.org/10.3201/eid1402.071024

Beier, J., R. S. Lees, D. D. Chadee, and J. R. L. Gilles (eds.). 2014. Biology and behaviour of male mosquitoes in relation to new approaches to control disease transmitting mosquitoes. Acta Tropica 132(Suppl.): S1-S188. https://www.sciencedirect.com/journal/acta-tropica/vol/132/supp1/S

Bellini, R., M. Calvitti, A. Medici, M. Carrieri, G. Celli, and S. ïini. 2007. Use of the sterile insect technique against Aedes albopictus in Italy: first results of a pilot trial, pp. 505-515. In M. J. B. Vreysen, A. S. Robinson and J. Hendrichs (eds.), Area-wide control of insect pests. From research to field implementation. Springer, Dordrecht, The Netherlands. https://www.iaea.org/sites/default/files/area-wide-control-insect-pests-book.pdf

Bellini, R., F. Balestrino, A. Medici, G. Gentile, R. Veronesi, and M. Carrieri. 2013a. Mating competitiveness of Aedes albopictus radio-sterilized males in large enclosures exposed to natural conditions. Journal of Medical Entomology 50: 94-102. https://doi.org/10.1603/ME11058

Bellini, R., A. Medici, A. Puggioli, F. Balestrino, and M. Carrieri. 2013b. Pilot field trials with Aedes albopictus irradiated sterile males in Italian urban areas. Journal of Medical Entomology 50: 317-325. https://doi.org/10.1603/ME12048

Bellini, R., A. Puggioli, F. Balestrino, M. Carrieri, and S. Urbanelli. 2018. Exploring protandry and pupal size selection for Aedes albopictus sex separation. Parasites and Vectors 11(Suppl. 2): 650. https://doi.org/10.1186/s13071-018-3213-x

Benavente-Sánchez, D., J. Moreno-Molina, and R. Argilés-Herrero. 2021. Prospects for remotely piloted aircraft systems in area-wide integrated pest management programmes, pp. 903-916. In J. Hendrichs, R. Pereira and M. J. B. Vreysen (eds.), Area-wide integrated pest management. Development and field application. CRC Press, Boca Raton, FL, USA.

Benedict, M. Q., and A. S. Robinson. 2003. The first releases of transgenic mosquitoes: an argument for the sterile insect technique. Tr. Para. 19(8): 349-355. https://doi.org/10.1016/S1471-4922(03)00144-2

Benedict, M. Q., A. S. Robinson, and B. G. J. Knols (eds.). 2009a. Development of the sterile insect technique for African malaria vectors. Malaria Journal 8(2). https://malariajournal.biomedcentral.com/articles/supplements/volume-8-supplement-2

Benedict, M. Q., B. G. J. Knols, H. C. Bossin, P. I. Howell, E. Mialhe, C. Caceres, and A. S. Robinson. 2009b. Colonisation and mass rearing: learning from others. Malaria Journal 8(Suppl. 2): S4. 
https://malariajournal.biomedcentral.com/articles/10.1186/1475-2875-8-S2-S4

Bernardini, F., R. E. Haghighat-Khah, R. Galizi, A. M. Hammond, T. Nolan, and A. Crisanti. 2018. Molecular tools and genetic markers for the generation of transgenic sexing strains in Anopheline mosquitoes. Parasites and Vectors 11(Suppl. 2): 660. https://doi.org/10.1186/s13071-018-3207-8

Bhatt, S., P. W. Gething, O. J. Brady, J. P. Messina, A. W. Farlow, C. L. Moyes, J. M. Drake, J. S. Brownstein, A. G. Hoen, O. Sankoh, M. F. Myers, D. B. George, T. Jaenisch, G. R. W. Wint, C. P. Simmons, T. W. Scott, J. J. Farrar, and S. I. Hay. 2013. The global distribution and burden of dengue. Nature 496: 504-507. https://www.nature.com/articles/nature12060

Bimbilé Somda, N. S., K. R. Dabiré, H. Maiga, H. Yamada, W. Mamai, O. Gnankiné, A. Diabaté, A. Sanon, J. Bouyer, and J. L. Gilles. 2017. Cost-effective larval diet mixtures for mass rearing of Anopheles arabiensis Patton (Diptera: Culicidae). Parasites and Vectors 10: 619. https://doi.org/10.1186/s13071-017-2552-3

Bimbilé Somda, N. S., B. S. Poda, P. S. Sawadogo, O. Gnankiné, H. Maiga, F. Fournet, R. S. Lees, J. Bouyer, J. Gilles, A. Sanon, A. Diabaté, and K. R. Dabiré. 2018. Ecology of reproduction of Anopheles arabiensis in an urban area of Bobo-Dioulasso, Burkina Faso (West Africa): monthly swarming and mating frequency and their relation to environmental factors. PLOS ONE 13(11): e0205966. https://doi.org/10.1371/journal.pone.0205966

Bimbilé Somda, N. S., H. Maïga, W. Mamai, H. Yamada, A. Ali, A. Konczal, O. Gnankiné, A. Diabaté, A. Sanon, K. R. Dabiré, J. R. L. Gilles, and J. Bouyer. 2019. Insects to feed insects feeding Aedes mosquitoes with flies for laboratory rearing. Scientific Reports 9: 11403. https://doi.org/10.1038/s41598-019-47817-x

Bourtzis, K. 2019. Successful completion of the CRP D44001 - exploring genetic, molecular, mechanical and behavioural methods of sex separation in mosquitoes. IAEA success story, 25 April 2019. https://www.iaea.org/newscenter/news/successful-completion-of-the-crp-d44001-exploring-geneticmolecular-mechanical-and-behavioural-methods-of-sex-separation-in-mosquitoes

Bourtzis, K., and J. Hendrichs. 2014. Development and evaluation of improved strains of insect pests for sterile insect technique (SIT) applications. BMC Genetics 15(Suppl. 2): I1 https://doi.org/10.1186/1471-2156-15-S2-I1

Bourtzis, K., and A. S. Robinson. 2006. Insect pest control using Wolbachia and/or radiation, pp. 225246. In K. Bourtzis and T. A. Miller (eds.), Insect symbiosis, Vol. 2. CRC Press, FL, USA. https://www.crcpress.com/Insect-Symbiosis-Volume-2/Bourtzis-Miller/p/book/9780849341946

Bourtzis, K., and Z. J. Tu (eds.). 2018. Exploring genetic, molecular, mechanical and behavioural methods of sex separation in mosquitoes. Parasites and Vectors 11(Suppl. 2). https://parasitesandvectors.biomedcentral.com/articles/supplements/volume-11-supplement-2

Bourtzis, K., S. L. Dobson, Z. Xi, J. L. Rasgon, M. Calvitti, L. A. Moreira, H. C. Bossin, R. Moretti, L. A. Baton, G. L. Hughes, P. Mavingui, and J. R. L. Gilles. 2014. Harnessing mosquito-Wolbachia symbiosis for vector and disease control. Acta Tropica 132(Suppl.): S150-S163. https://doi.org/10.1016/j.actatropica.2013.11.004

Bourtzis, K., R. S. Lees, J. Hendrichs, and M. J. B. Vreysen. 2016. More than one rabbit out of the hat: radiation, transgenic and symbiont-based approaches for sustainable management of mosquito and tsetse fly populations. Acta Tropica 157: 115-130. https://doi.org/10.1016/j.actatropica.2016.01.009

Bouyer, J., and T. Lefrançois. 2014. Boosting the sterile insect technique to control mosquitoes. Trends in Parasitology 30(6): 271-273. https://doi.org/10.1016/j.pt.2014.04.002

Bouyer, J., and E. Marois. 2018. Genetic control of vectors. In Pests and vector-borne diseases in the livestock industry (p. e0121126). Wageningen Academic Publishers, Wageningen, The Netherlands.

Bouyer, J., F. Chandre, J. Gilles, and T. Baldet. 2016. Alternative vector control methods to manage the Zika virus outbreak: more haste, less speed. The Lancet Global Health 4(6): e364. https://doi.org/10.1016/S2214-109X(16)00082-6

Bouyer, J., H. Yamada, R. Pereira, K. Bourtzis, and M. J. B. Vreysen. 2020. Phased conditional approach for mosquito management using sterile insect technique. Trends in Parasitology 36: 325-336. https://doi.org/10.1016/j.pt.2020.01.004

Bown, J. 2019. The sea-cooled eco-resort that's nearly mosquito-free. BBC Business News, 31 May 2019. https://www.bbc.com/news/business-48380590

Braga, I. A., and D. Valle. 2007. Aedes aegypti: history of control in Brazil. Epidemiologia e Serviços de Saúde 16(2): 113-118. http://bvsms.saude.gov.br/bvs/periodicos/rev_epi_vol16_n2.pdf

Breeland, S. G., G. M. Jeffery, C. S. Lofgren, and D. E. Weidhaas. $197 \overline{4}$. Release of chemosterilized males for the control of Anopheles albimanus in El Salvador. I. Characteristics of the test site and the natural population. The American Journal of Tropical Medicine and Hygiene 23(2): 274-281. 
Brelsfoard, C. L., W. St. Clair, and S. L. Dobson. 2009. Integration of irradiation with cytoplasmic incompatibility to facilitate a lymphatic filariasis vector elimination approach. Parasites and Vectors 2 : 38. https://doi.org/10.1186/1756-3305-2-38

Carrieri, M., A. Albieri, P. Angelini, F. Baldacchini, C. Venturelli, S. M. Zeo, and R. Bellini. 2011. Surveillance of the chikungunya vector Aedes albopictus (Skuse) in Emilia-Romagna (northern Italy): organizational and technical aspects of a large scale monitoring system. Journal of Vector Ecology 36: 108-116. https://doi.org/10.1111/j.1948-7134.2011.00147.x

Carvalho, D. O., D. Nimmo, N. Naish, A. R. McKemey, P. Gray, A. B. Wilke, M. T. Marrelli, J. F. Virginio, L. Alphey, and M. L. Capurro. 2014. Mass production of genetically modified Aedes aegypti for field releases in Brazil. J. Vis. Exp. 83: e3579. https://www.jove.com/video/3579/massproduction-genetically-modified-aedes-aegypti-for-field-releases

Carvalho, D. O., A. R. McKemey, L. Garziera, R. Lacroix, C. A. Donnelly, L. Alphey, A. Malavasi, and M. L. Capurro. 2015. Suppression of a field population of Aedes aegypti in Brazil by sustained release of transgenic male mosquitoes. PLOS Neglected Tropical Diseases 9(7): e0003864. https://doi.org/10.1371/journal.pntd.0003864

Catteruccia, F., A. Crisanti, and E. A. Wimmer. 2009. Transgenic technologies to induce sterility. Malaria Journal 8(Suppl. 2): S7. https://doi.org/10.1186/1475-2875-8-S2-S7

(CBD) Convention on Biological Diversity. 2014. The Nagoya Protocol on access to genetic resources and the fair and equitable sharing of benefits arising from their utilization to the Convention on Biological Diversity. https://www.cbd.int/abs/

Chung, H. N., S. D. Rodriguez, K. K. Gonzales, J. Vulcan, J. J. Cordova, S. Mitra, C. G. Adams, N. Moses-Gonzales, N. Tam, J. W. Cluck, G. M. Attardo, and I. A. Hansen. 2018. Toward implementation of mosquito sterile insect technique: the effect of storage conditions on survival of male Aedes aegypti mosquitoes (Diptera: Culicidae) during transport. Journal of Insect Science 18(6)(2): 1 7. https://doi.org/10.1093/jisesa/iey103

Co, C. 2019. New facility to produce up to 5 million Wolbachia mosquitoes weekly in fight against dengue. Channel News Asia, 2 Dec. https://www.channelnewsasia.com/news/singapore/wolbachiamosquitoes-new-facility-aedes-aegypti-dengue-12145012

Codeço, C. T., A. W. S. Lima, S. C. Araújo, J. B. P. Lima, R. Maciel-de-Freitas, N. A. Honório, A. K. R. Galardo, I. A. Braga, G. E. Coelho, and D. Valle. 2015. Surveillance of Aedes aegypti: comparison of house index with four alternative traps. PLOS Neglected Tropical Diseases 9(2): e0003475. https://doi.org/10.1371/journal.pntd.0003475

Culbert, N. J., R. S. Lees, M. J. B. Vreysen, A. C. Darby, and J. R. L. Gilles. 2017. Optimised conditions for handling and transport of male Anopheles arabiensis: effects of low temperature, compaction, and ventilation on male quality. Entomologia Experimentalis et Applicata 164(3, Special Issue): 276-283. https://doi.org/10.1111/eea.12610

Culbert, N. J., F. Balestrino, A. Dor, G. S. Herranz, H. Yamada, T. Wallner, and J. Bouyer. 2018a. A rapid quality control test to foster the development of genetic control in mosquitoes. Scientific Reports 8(16179): 1-9. https://www.nature.com/articles/s41598-018-34469-6

Culbert, N. J., H. Maiga, N. S. Bimbile Somda, J. R. L. Gilles, J. Bouyer, and W. Mamai. $2018 b$. Longevity of mass-reared, irradiated and packed male Anopheles arabiensis and Aedes aegypti under simulated environmental field conditions. Parasites and Vectors 11: 603. https://doi.org/10.1186/s13071-018-3191-z

Dame, D. A., C. S. Lofgren, H. R. Ford, M. D. Boston, K. F. Baldwin, and G. M. Jeffery. 1974. Release of chemosterilized males for the control of Anopheles albimanus in El Salvador. II. Methods of rearing, sterilization, and distribution. American J. of Tropical Medicine and Hygiene 23(2): 282-287.

Dame, D. A., C. F. Curtis, M. Q. Benedict, A. S. Robinson, and B. G. J. Knols. 2009. Historical applications of induced sterilisation in field populations of mosquitoes. Malaria Journal 8(Suppl. 2): S2. https://doi.org/10.1186/1475-2875-8-S2-S2

Damiens, D., M. Q. Benedict, M. Wille, and J. R. L. Gilles. 2012. An inexpensive and effective larval diet for Anopheles arabiensis (Diptera: Culicidae): eat like a horse, a bird, or a fish? Journal of Medical Entomology 49: 1001-1011. https://doi.org/10.1603/ME11289

Damiens, D., S. M. Soliban, F. Balestrino, R. Alsir, M. J. B. Vreysen, and J. R. L. Gilles. 2013. Different blood and sugar feeding regimes affect the productivity of Anopheles arabiensis colonies (Diptera: Culicidae). Journal of Medical Entomology 50: 336-343. https://doi.org/10.1603/ME12212

Damiens, D., P. O. Tjeck, C. Lebon, G. Le Goff, and L. C. Gouagna. 2016. The effects of age at first mating and release ratios on the mating competitiveness of gamma sterilised Aedes albopictus males under semi field conditions. Vector Biology Journal 2(1). DOI: 10.4172/2473-4810.1000107 
https://www.scitechnol.com/peer-review/the-effects-of-age-at-first-mating-and-release-ratios-on-themating-competitiveness-of-gamma-sterilised-iaedes-albopictusi-malesun-mqLU.php?article_id=4871

Darrow, D. I. 1968. The effect of gamma irradiation on reproduction and life span of the mosquito Culex tarsalis Coquillet. Mosq. News 28: 21-24. https://www.cabdirect.org/cabdirect/abstract/19701000127

Debug-Verily. 2019. Let's stop bad bugs with good bugs. https://debug.com/ https://newatlas.com/verily-mosquito-release-wolbachia/50521/

Diallo, S., M. T. Seck, J. B. Rayaissé, A. G. Fall, M. D. Bassene, B. Sall, A. Sanon, M. J. B. Vreysen, P. Takac, A. G. Parker, G. Gimonneau, and J. Bouyer. 2018. Chilling, irradiation and transport of male Glossina palpalis gambiensis pupae: effect on the emergence, flight ability and survival. BioRxiv: 502567. https://www.biorxiv.org/content/10.1101/502567v1 https://doi.org/10.1101/502567

Dzul-Manzanilla, F., J. Ibarra-López, W. B. Marín, A. Martini-Jaimes, J. T. Leyva, F. CorreaMorales, H. Huerta, P. Manrique-Saide, and G. M. Vazquez-Prokopec. 2017. Indoor resting behavior of Aedes aegypti (Diptera: Culicidae) in Acapulco, Mexico. Journal of Medical Entomology 54(2): 501-504. https://doi.org/10.1093/jme/tjw203

Eckermann, K. N., S. Dippel, M. KaramiNejadRanjbar, H. M. Ahmed, I. M. Curril, and E. A. Wimmer. 2014. Perspective on the combined use of an independent transgenic sexing and a multifactorial reproductive sterility system to avoid resistance development against transgenic sterile insect technique approaches. BMC Gen. 15(S. 2): S17. https://doi.org/10.1186/1471-2156-15-S2-S17

Edillo, F. E., Y. A. Halasa, F. M. Largo, J. N. V. Erasmo, N. B. Amoin, M. T. P. Alera, I. K. Yoon, A. C. Alcantara, and D. S. Shepard. 2015. Economic cost and burden of dengue in the Philippines. American J. of Tropical Medicine and Hygiene 92(2): 360-366. https://doi.org/10.4269/ajtmh.14-0139

Eiras, A. E., M. C. Resende, J. L. Acebal, and K. S. Paixão. 2018. New cost-benefit of Brazilian technology for vector surveillance using trapping system. In From local to global impact of mosquitoes. https://www.intechopen.com/online-first/new-cost-benefit-of-brazilian-technology-for-vectorsurveillance-using-trapping-system DOI: 10.5772/intechopen.78781

Enkerlin, W., J. M. Gutiérrez-Ruelas, A. V. Cortes, E. C. Roldan, D. Midgarden, E. Lira, J. L. Z. López, J. Hendrichs, P. Liedo, and F. J. T. Arriaga. 2015. Area freedom in Mexico from Mediterranean fruit fly (Diptera: Tephritidae): a review of over 30 years of a successful containment program using an integrated area-wide SIT approach. Florida Entomologist 98(2): 665-681. http://journals.fcla.edu/flaent/article/view/84899

Facchinelli, L., L. Valerio, J. M. Ramsey, F. Gould, R. K. Walsh, G. Bond, M. A. Robert, A. L. Lloyd, A. A. James, L. Alphey, and T. W. Scott. 2013. Field cage studies and progressive evaluation of genetically-engineered mosquitoes. PLOS Neglected Tropical Diseases 7(1): e2001. https://doi.org/10.1371/journal.pntd.0002001

(FAO/IAEA) Food and Agriculture Organization of the United Nations/International Atomic Energy Agency. 2014. Mosquito handling, transport and release methods. Report of a consultants group meeting held 8-12 December 2014 in Vienna, Austria. http://www-naweb.iaea.org/nafa/ipc/public/Consultants-Meeting-Report-Mosquito-Release.pdf

(FAO/IAEA) Food and Agriculture Organization of the United Nations/International Atomic Energy Agency. 2015. Preventing procreation: the IAEA's research for mosquito control. Photo essay. https://www.iaea.org/newscenter/multimedia/photoessays/preventing-procreation-iaeas-researchmosquito-control

(FAO/IAEA) Food and Agriculture Organization of the United Nations/International Atomic Energy Agency. 2016a. Drones for good 2016: FAO/IAEA's ROMEO system for aerial release of sterile male mosquitoes. Video. http://www-naweb.iaea.org/nafa/ipc/romeo-joint-fao-iaea.mp4

(FAO/IAEA) Food and Agriculture Organization of the United Nations/International Atomic Energy Agency. 2016b. Zika crisis - the IAEA responds. https://www.youtube.com/watch? $v=n F$ ixznCabE

(FAO/IAEA) Food and Agriculture Organization of the United Nations/International Atomic Energy Agency. 2017a. Guidelines for standardised mass rearing of Anopheles mosquitoes, version 1.0. http://www-naweb.iaea.org/nafa/ipc/public/Guidelines-for-standardised-mass-rearing-of-Anophelesmosquitoes-v1.0.pdf

(FAO/IAEA) Food and Agriculture Organization of the United Nations/International Atomic Energy Agency. 2017b. Guidelines for routine colony maintenance of Aedes mosquito species, version 1.0. http://www-naweb.iaea.org/nafa/ipc/public/guidelines-for-routine-colony-maintenance-of-Aedesmosquito-species-v1.0.pdf

(FAO/IAEA) Food and Agriculture Organization of the United Nations/International Atomic Energy Agency. 2018a. IAEA conducts successful test of drones in fight against disease-transmitting mosquitos. Press release, 19 April 2018. IAEA, Vienna Austria. 
https://www.iaea.org/newscenter/pressreleases/iaea-conducts-successful-test-of-drones-in-fight-againstdisease-transmitting-mosquitos

(FAO/IAEA) Food and Agriculture Organization of the United Nations/International Atomic Energy Agency. 2018b. Guidelines for colonization of Aedes mosquito species, version 1.0. http://wwwnaweb.iaea.org/nafa/ipc/public/Guidelines-for-colonisation-of-Aedes-mosquito-species-v1.0.final.pdf

(FAO/IAEA) Food and Agriculture Organization of the United Nations/International Atomic Energy Agency. 2018c. Insect Pest Control Newsletter No. 91, July 2018. https://www.iaea.org/publications/13399/insect-pest-control-newsletter-no-91-july-2018

(FAO/IAEA) Food and Agriculture Organization of the United Nations/International Atomic Energy Agency. 2019a. Mosquito handling, transport, release and male trapping methods. FAO/IAEA Coordinated Research Project. http://www-naweb.iaea.org/nafa/ipc/crp/ipc-mosquito-handling.html

(FAO/IAEA) Food and Agriculture Organization of the United Nations/International Atomic Energy Agency. 2019b. Thematic plan for the development and application of the sterile insect technique (SIT) and related genetic and biological control methods for disease transmitting mosquitoes. Vienna, Austria. 93 pp. http://www-naweb.iaea.org/nafa/ipc/public/Thematic-Plan-2019-final.pdf

Fay, R. W., and H. B. Morlan. 1959. A mechanical device for separating the developmental stages, sexes and species of mosquitoes. Mosquito News 19(3): 144-147. https://www.cabdirect.org/cabdirect/abstract/19611000385

Flores, H. A., and S. L. O'Neill. 2018. Controlling vector-borne diseases by releasing modified mosquitoes. Nat. Rev. Micro. 16: 508-518. https://www.nature.com/articles/s41579-018-0025-0

Focks, D. A. 1980. An improved separator for the developmental stages, sexes, and species of mosquitoes (Diptera: Culicidae). J. Medical Entomology 17: 567-568. https://doi.org/10.1093/jmedent/17.6.567

Foley IV, E. W., R. L. Morreale, D. F. Hoel, and A. M. Lloyd. 2021. Area-wide mosquito management in Lee County, Florida, USA, pp. 319-338. In J. Hendrichs, R. Pereira and M. J. B. Vreysen (eds.), Area-wide integrated pest management. Development and field application. CRC Press, Boca Raton.

Gilles, J. R. L., M. F. Schetelig, F. Scolari, F. Marec, M. L. Capurro, G. Franz, and K. Bourtzis. 2014. Towards mosquito sterile insect technique programmes: exploring genetic, molecular, mechanical and behavioural methods of sex separation in mosquitoes. Acta Tropica 132(Suppl.): S178-S187. https://doi.org/10.1016/j.actatropica.2013.08.015

Golding, N., A. L. Wilson, C. L. Moyes, J. Cano, D. M. Pigott, R. Velayudhan, S. J. Brooker, D. L. Smith, S. I. Hay, and S. W. Lindsay. 2015. Integrating vector control across diseases. BMC Medicine 13: 249. https://doi.org/10.1186/s12916-015-0491-4

Gorman, K., J. Young, L. Pineda, R. Márquez, N. Sosa, D. Bernal, R. Torres, Y. Soto, R. Lacroix, N. Naish, P. Kaiser, K. Tepedino, G. Philips, C. Kosmann, and L. Cáceres. 2015. Short-term suppression of Aedes aegypti using genetic control does not facilitate Aedes albopictus. Pest Management Science 72(3): 618-628. https://doi.org/10.1002/ps.4151

Gossner, C. M., E. Ducheyne, and F. Schaffner. 2018. Increased risk for autochthonous vector-borne infections transmitted by Aedes albopictus in continental Europe. Eurosurveillance 23(24)(14 June). https://www.eurosurveillance.org/content/10.2807/1560-7917.ES.2018.23.24.1800268

Griffing, S. M., P. L. Tauil, V. Udhayakumar, and L. Silva-Flannery. 2015. A historical perspective on malaria control in Brazil. Memórias Do Instituto Oswaldo Cruz 110(6): 701-718.

https://memorias.ioc.fiocruz.br/article/6030/0041_a-historical-perspective-on-malaria-control-in-brazil DOI: 10.1590/0074-02760150041

Grigoraki, L., D. Pipini, P. Labbé, A. Chaskopoulou, M. Weill, and J. Vontas. 2017. Carboxylesterase gene amplifications associated with insecticide resistance in Aedes albopictus: geographical distribution and evolutionary origin. PLOS Neglected Tropical Diseases 11(4): e0005533. https://doi.org/10.1371/journal.pntd.0005533

Häcker, I., and M. F. Schetelig. 2018. Molecular tools to create new strains for mosquito sexing and vector control. Parasites and Vectors 11(Suppl. 2): 645. https://doi.org/10.1186/s13071-018-3209-6

Hall, A. B., S. Basu, X. Jiang, Y. Qi, V. A. Timoshevskiy, J. K. Biedler, M. V. Sharakhova, R. Elahi, M. A. E. Anderson, X. G. Chen, I. V. Sharakhov, Z. N. Adelman, and Z. Tu. 2015. A maledetermining factor in the mosquito Aedes aegypti. Science 348(6240): 1268-1270. http://science.sciencemag.org/content/348/6240/1268 DOI: $10.1126 /$ science.aaa2850

Handler, A. M. 2016. Enhancing the stability and ecological safety of mass-reared transgenic strains for field release by redundant conditional lethality systems. Insect Science 23: 225-234. https://doi.org/10.1111/1744-7917.12245

Haridy, R. 2017. 20 million sterile mosquitoes to be releasesd in California. https://newatlas.com/verily-mosquito-release-wolbachia/50521/ 
Harris, A. F., D. Nimmo, A. R. McKemey, N. Kelly, S. Scaife, C. A. Donnelly, C. Beech, W. D. Petrie, and L. Alphey. 2011. Field performance of engineered male mosquitoes. Nature Biotechnology 29: 1034-1037. https://www.nature.com/articles/nbt.2019

Helinski, M. E. H., A. G. Parker, and B. G. J. Knols. 2006. Radiation-induced sterility for pupal and adult stages of the malaria mosquito Anopheles arabiensis. Malaria Journal 5: 41. https://doi.org/10.1186/1475-2875-5-41

Helinski, M. E. H., M. M. Hassan, W. M. El-Motasim, C. A. Malcolm, B. G. J. Knols, and B. ElSayed. 2008. Towards a sterile insect technique field release of Anopheles arabiensis mosquitoes in Sudan: irradiation, transportation, and field cage experimentation. Malaria Journal 7: 65 . https://doi.org/10.1186/1475-2875-7-65

Helinski, M. E. H., A. G. Parker, and B. G. J. Knols. 2009. Radiation biology of mosquitoes. Malaria Journal 8(Suppl. 2): S6. https://doi.org/10.1186/1475-2875-8-S2-S6

Hoffmann, A. A., B. L. Montgomery, J. Popovici, I. Iturbe-Ormaetxe, P. H. Johnson, F. Muzzi, M. Greenfield, M. Durkan, Y. S. Leong, Y. Dong, H. Cook, J. Axford, A. G. Callahan, N. Kenny, C. Omodei, E. A. McGraw, P. A. Ryan, S. A. Ritchie, M. Turelli, and S. L. O’Neill. 2011. Successful establishment of Wolbachia in Aedes populations to suppress dengue transmission. Nature 476: 454 457. https://www.nature.com/articles/nature10356 https://doi.org/10.1038/nature10356

Honório, N. A., W. D. C. Silva, P. J. Leite, J. M. Gonçalves, L. P. Lounibos, and R. Lourenço-deOliveira. 2003. Dispersal of Aedes aegypti and Aedes albopictus (Diptera: Culicidae) in an urban endemic dengue area in the State of Rio de Janeiro, Brazil. Memórias do Instituto Oswaldo Cruz 98(2): 191-198. http://www.scielo.br/pdf/mioc/v98n2/v98n2a05.pdf

Howell, P. I., and B. G. J. Knols. 2009. Male mating biology. Malaria Journal 8(Suppl. 2): S8. https://doi.org/10.1186/1475-2875-8-S2-S8

Iyaloo, D. P., and S. Facknath. 2017. Optimization of Aedes albopictus rearing procedures: preliminary steps towards large-scale rearing of the species within the laboratory in Mauritius. Journal of Entomology and Zoology Studies 5(2): 46-53. http://www.entomoljournal.com/archives/2017/vol5issue2/PartA/5-1-176-772.pdf

Iyaloo, D. P., K. B. Elahee, A. Bheecarry, and R. S. Lees. 2014. Guidelines to site selection for population surveillance and mosquito control trials: a case study from Mauritius. Acta Tropica 132(Suppl.): S140-S149. https://doi.org/10.1016/j.actatropica.2013.11.011

Iyaloo, D. P., D. Damiens, S. Facknath, K. B. Elahee, and A. Bheecarry. 2019. Dispersal and survival of radio-sterilised male Aedes albopictus Skuse (Diptera: Culicidae) and estimation of the wild populations in view of an sterile insect technique programme in Pointe des Lascars, Mauritius. International J. of Tropical Insect Science 39: 63-72. https://doi.org/10.1007/s42690-019-00017-6

Johnson, B. J., B. B. Rohde, N. Zeak, K. M. Staunton, T. Prachar, and S. A. Ritchie. 2018. A lowcost, battery-powered acoustic trap for surveilling male Aedes aegypti during rear-and-release operations. PLOS ONE 13(8): e0201709. https://doi.org/10.1371/journal.pone.0201709

Jozuka, E. 2016. Inside China's 'mosquito factory' fighting Zika and dengue. CNN report. https://edition.cnn.com/2016/12/28/health/china-mosquito-factory-zika-dengue/

Justia Patents. 2017. Sieving devices for pupae separation. https://patents.justia.com/patent/10342222

Kandul, N. P., J. Liu, H. M. Sanchez C., S. L. Wu, J. M. Marshall, and O. S. Akbari. 2019. Transforming insect population control with precision guided sterile males with demonstration in flies. Nature Communications 10: 84. https://www.nature.com/articles/s41467-018-07964-7

Khan, I., A. Farid, and A. Zeb. 2013. Development of inexpensive and glaboally available larval diet for rearing Anopheles stephensi (Diptera: Culicidae) mosquitoes. Parasites and Vectors 6: 90. https://doi.org/10.1186/1756-3305-6-90

Kittayapong, P. 2021. Combined sterile insect technique and incompatible insect technique: concept, study design, experience and lessons learned from a pilot suppression trial in Thailand, pp. 405-432. In J. Hendrichs, R. Pereira and M. J. B. Vreysen (eds.), Area-wide integrated pest management. Development and field application. CRC Press, Boca Raton, FL, USA.

Kittayapong, P., N. O. Kaeothaisong, S. Ninphanomchai, and W. Limohpasmanee. 2018. Combined sterile insect technique and incompatible insect technique: sex separation and quality of sterile Aedes aegypti male mosquitoes released in a pilot population suppression trial in Thailand. Parasites and Vectors 11(Suppl. 2): 657. https://doi.org/10.1186/s13071-018-3214-9

Kraemer, M. U. G., M. E. Sinka, K. A. Duda, A. Q. N. Mylne, F. M. Shearer, C. M. Barker, C. G. Moore, R. G. Carvalho, G. E. Coelho, W. Van Bortel, G. Hendrickx, F. Schaffner, I. R. F. Elyazar, H. J. Teng, O. J. Brady, J. P. Messina, D. M. Pigott, T. W. Scott, D. L. Smith, G. R. W. 
Wint, N. Golding, and S. I. Hay. 2015. The global distribution of the arbovirus vectors Aedes aegypti and Ae. albopictus. eLife 4: e08347. https://elifesciences.org/articles/08347 DOI: 10.7554/eLife.08347

Krafsur, E. S. 1998. Sterile insect technique for suppressing and eradicating insect population: 55 years and counting. J. Agric. Entomol. 15(4): 303-317. http://scentsoc.org/Volumes/JAE/v15/4/00154303.pdf

Lebon, C., A. Benlali, C. Atyame, P. Mavingui, and P. Tortosa. 2018. Construction of a genetic sexing strain for Aedes albopictus: a promising tool for the development of sterilizing insect control strategies targeting the tiger mosquito. Parasites and Vectors 11(Suppl. 2): 658. https://doi.org/10.1186/s13071-018-3212-y

Lees, R. S., B. Knols, R. Bellini, M. Q. Benedict, A. Bheecarry, H. C. Bossin, D. D. Chadee, J. Charlwood, R. K. Dabiré, L. Djogbenou, A. Egyir-Yawson, R. Gato, L. C. Gouagna, M. M. Hassan, S. A. Khan, L. L. Koekemoer, G. Lemperiere, N. C. Manoukis, R. Mozuraitis, R. J. Pitts, F. Simard, and J. R. L. Gilles. 2014. Review: improving our knowledge of male mosquito biology in relation to genetic control programmes. Acta Tropica 132(Suppl.): S2-S11. https://doi.org/10.1016/j.actatropica.2013.11.005

Lees, R. S., J. R. L. Gilles, J. Hendrichs, M. J. B. Vreysen, and K. Bourtzis. 2015. Back to the future: the sterile insect technique against mosquito disease vectors. Current Opinion in Insect Science 10: 156-162. https://doi.org/10.1016/j.cois.2015.05.011

Liew, C., L. T. Soh, I. Chen, X. Li, S. Sim, and L. C. Ng. 2021. Community engagement for Wolbachiabased dengue control: the Singapore experience, pp. 747-761. In J. Hendrichs, R. Pereira and M. J. B. Vreysen (eds.), Area-wide integrated pest mangement. Development and field application. CRC Press, Boca Raton, FL, USA.

Lutrat, C., D. Giesbrecht, E. Marois, S. Whyard, T. Baldet, and J. Bouyer. 2019. Sex sorting for pest control: it's raining men! Trends in Parasit. 35(8): 649-662. https://doi.org/10.1016/j.pt.2019.06.001

Madakacherry, O., R. S. Lees, and J. R. L. Gilles. 2014. Aedes albopictus (Skuse) males in laboratory and semi-field cages: release ratios and mating competitiveness. Acta Tropica 132(Suppl.): S124-S129. https://doi.org/10.1016/j.actatropica.2013.11.020

Maïga, H., D. Damiens, A. Diabaté, R. K. Dabiré, G. A. Ouédraogo, R. S. Lees, and J. R. L. Gilles. 2016. Large-scale Anopheles arabiensis egg quantification methods for mass-rearing operations. Malaria Journal 15: 72. https://doi.org/10.1186/s12936-016-1119-7

Maïga, H., N. S. Bimbilé-Somda, H. Yamada, O. Wood, D. Damiens, W. Mamai, F. Balestrino, R. S. Lees, R. K. Dabiré, A. Diabaté, and J. R. L. Gilles. 2017. Enhancements to the mass-rearing cage for the malaria vector, Anopheles arabiensis for improved adult longevity and egg production. Entomologia Experimentalis et Applicata 164(3)(Sp. Is.): 269-275. https://doi.org/10.1111/eea.12614

Maïga, H., W. Mamai, N. S. Bimbilé Somda, A. Konczal, T. Wallner, G. S. Herranz, R. Argiles Herrero, H. Yamada, and J. Bouyer. 2019. Reducing the cost and assessing the performance of a novel adult mass-rearing cage for the dengue, chikungunya, yellow fever and Zika vector, Aedes aegypti (Linnaeus). PLOS Neglected Tropical Diseases 13(9): e0007775. https://doi.org/10.1371/journal.pntd.0007775

Mains, J. W., C. L. Brelsfoard, and S. L. Dobson. 2015. Male mosquitoes as vehicles for insecticide. PLOS Neglected Tropical Diseases 9(1): e0003406. https://doi.org/10.1371/journal.pntd.0003406

Mains, J. W., C. L. Brelsfoard, R. I. Rose, and S. L. Dobson. 2016. Female adult Aedes albopictus suppression by Wolbachia-infected male mosquitoes. Scientific Reports 6: 33846. https://www.nature.com/articles/srep33846

Mains, J. W., P. H. Kelly, K. L. Dobson, W. D. Petrie, and S. L. Dobson. 2019. Localized control of Aedes aegypti (Diptera: Culicidae) in Miami, FL, via inundative releases of Wolbachia-infected male mosquitoes. Journal of Medical Entomology 56: 1296-1303. https://doi.org/10.1093/jme/tjz051

Mamai, W., R. Hood-Nowotny, H. Maiga, A. B. Ali, N. S. Bimbile-Somda, D. D. Soma, H. Yamada, R. S. Lees, and J. R. L. Gilles. 2017. Reverse osmosis and ultrafiltration for recovery and reuse of larval rearing water in Anopheles arabiensis mass production: effect of water quality on larval development and fitness of emerging adults. Acta Tropica 170: 126-133. https://doi.org/10.1016/j.actatropica.2017.02.033

Mamai, W., L. N. Lobb, N. S. Bimbilé Somda, H. Maiga, H. Yamada, R. S. Lees, J. Bouyer, and J. R. L. Gilles. 2018. Optimization of mass-rearing methods for Anopheles arabiensis larval stages: effects of rearing water temperature and larval density on mosquito life-history traits. Journal of Economic Entomology 111(5): 2383-2390. https://doi.org/10.1093/jee/toy213

Mamai, W., H. Maiga, M. Gárdos, P. Bán, N. S. Bimbilé Somda, A. Konczal, T. Wallner, A. Parker, F. Balestrino, H. Yamada, J. R. L. Gilles, and J. Bouyer. 2019. The efficiency of a new automated mosquito larval counter and its impact on larval survival. Scientific Reports 9: 7413. 
https://doi.org/10.1038/s41598-019-43333-0

Marois, E., C. Scali, J. Soichot, C. Kappler, E. A. Levashina, and F. Catteruccia. 2012. Highthroughput sorting of mosquito larvae for laboratory studies and for future vector control interventions. Malaria Journal 11: 302. https://doi.org/10.1186/1475-2875-11-302

Mashatola, T., C. Ndo, L. L. Koekemoer, L. C. Dandalo, O. R. Wood, L. Malakoane, Y. Poumachu, L. N. Lobb, M. Kaiser, K. Bourtzis, and G. Munhenga. 2018. A review on the progress of sexseparation techniques for sterile insect technique applications against Anopheles arabiensis. Parasites and Vectors 11(Suppl. 2): 646. https://doi.org/10.1186/s13071-018-3219-4

Mayer, S. V., R. B. Tesh, and N. Vasilakis. 2017. The emergence of arthropod-borne viral diseases: a global prospective on dengue, chikungunya and zika fevers. Acta Tropica 166: 155-163. https://doi.org/10.1016/j.actatropica.2016.11.020

McGraw, E. A., and S. L. O'Neill. 2013. Beyond insecticides: new thinking on ancient problem. Nature Reviews Microbiology 11: 181-193. https://www.nature.com/articles/nrmicro2968

Mitchell, C. J. 1995. The role of Aedes albopictus as an arbovirus vector. Parasitologia 37: 109-113.

Moretti, R., G. A. Marzo, E. Lampazzi, and M. Calvitti. 2018. Cytoplasmic incompatibility management to support incompatible insect technique against Aedes albopictus. Parasites and Vectors 11(Suppl. 2): 649. https://doi.org/10.1186/s13071-018-3208-7

Morlan, H. B., E. M. McCray, and J. W. Kilpatrick. 1962. Field tests with sexually sterile males for control of Aedes aegypti. Mosquito News 22(3): 295-300.

MosquitoMate. 2019. Responsible mosquito control. https://mosquitomate.com/?v=3.0

Moyes, C. L., J. Vontas, A. J. Martins, L. C. Ng, S. Y. Koou, I. Dusfour, K. Raghavendra, J. Pinto, V. Corbel, J. P. David, and D. Weetman. 2017. Contemporary status of insecticide resistance in the major Aedes vectors of arboviruses infecting humans. PLOS Neglected Tropical Diseases 11(7): e0005625. https://doi.org/10.1371/journal.pntd.0005625

Nabarro, D. 1999. Roll back malaria. Parasitologia 41(1-3): 501-504.

Ndo, C., H. Yamada, D. D. Damiens, S. N'do, G. Seballos, and J. R. L. Gilles. 2014. X-ray sterilization of the An. arabiensis genetic sexing strain 'ANO IPCL1' at pupal and adult stages. Acta Tropica 131: 124-128. https://doi.org/10.1016/j.actatropica.2013.11.027

Ndo, C., Y. Poumachu, D. Metitsi, H. P. Awono-Ambene, T. Tchuinkam, J. L. R. Gilles, and K. Bourtzis. 2018. Isolation and characterization of a temperature-sensitive lethal strain of Anopheles arabiensis for SIT-based application. Parasites and Vectors 11(Suppl. 2): 659. https://doi.org/10.1186/s13071-018-3216-7

(NEA) National Environment Agency. 2018. Impact assessment on the release of X-ray or similar treated Wolbachia-Aedes mosquitoes for suppression of the urban Aedes aegypti mosquito population. https://www.nea.gov.sg/docs/default-source/resource/impact-assessment-report.pdf

(NEA) National Environment Agency. 2019a. Project Wolbachia Singapore. Using male Wolbachiacarrying Aedes aegypti mosquitoes to help reduce the dengue mosquito population.

https://www.nea.gov.sg/corporate-functions/resources/research/wolbachia-aedes-mosquito-suppressionstrategy/project-wolbachia-singapore

(NEA) National Environment Agency. 2019b. New NEA facility to boost production of male Wolbachia-Aedes aegypti mosquitoes to benefit more residents.

https:/www.nea.gov.sg/media/news/news/index/new-nea-facility-to-boost-production-of-malewolbachia-aedes-aegypti-mosquitoes-to-benefit-more-residents

Ockenhouse, C. F., A. Magill, D. Smith, and W. Milhous. 2005. History of U.S. military contributions to the study of malaria. Military Medicine 170(Suppl. 4): 12-16. https://doi.org/10.7205/MILMED.170.4S.12

O'Connor, L., C. Plichart, A. C. Sang, C. L. Brelsfoard, H. C. Bossin, and S. L. Dobson. 2012. Open release of male mosquitoes infected with a Wolbachia biopesticide: field performance and infection containment. PLOS Neg. Trop. Diseases 6(11): e1797. https://doi.org/10.1371/journal.pntd.0001797

Oliva, C. F., M. J. B. Vreysen, S. Dupé, R. S. Lees, J. R. L. Gilles, L.-C. Gouagna, and R. Chhem. 2014. Current status and future challenges for controlling malaria with the sterile insect technique: technical and social perspectives. Acta Tropica 132(Suppl.): S130-S139. https://doi.org/10.1016/j.actatropica.2013.11.019

Oliveira, L. N. d. S., A. Itria, and E. C. Lima. 2019. Cost of illness and program of dengue: a systematic review. PLOS ONE 14(2): e0211401. https://doi.org/10.1371/journal.pone.0211401

Oxitec. 2019. Oxitec's friendly ${ }^{\mathrm{TM}}$ mosquito technology. https://www.oxitec.com/friendly-mosquitoes/ 
Papathanos, P. A., H. C. Bossin, M. Q. Benedict, F. Catteruccia, C. A. Malcolm, L. Alphey, and A. Crisanti. 2009. Sex separation strategies: past experience and new approaches. Malaria Journal 8(Suppl. 2): S5. https://doi.org/10.1186/1475-2875-8-S2-S5

Papathanos, P. A., K. Bourtzis, F. Tripet, H. Bossin, J. F. Virginio, M. L. Capurro, M. C. Pedrosa, A. Guindo, L. Sylla, M. B. Coulibaly, F. A. Yao, P. S. Epopa, and A. Diabate. 2018. A perspective on the need and current status of efficient sex separation methods for mosquito genetic control. Parasites and Vectors 11(Suppl. 2): 654. https://doi.org/10.1186/s13071-018-3222-9

Pepin, K. M., C. Marques-Toledo, L. Scherer, M. M. Morais, B. Ellis, and A. E. Eiras. 2013. Costeffectiveness of novel system of mosquito surveillance and control, Brazil. Emerging Infectious Diseases 19(4): 542-550. https://dx.doi.org/10.3201/eid1904.120117

Pessanha, J. E. M., W. T. Caiaffa, C. C. César, and F. A. Proietti. 2009. Evaluation of the Brazilian national dengue control plan. [English abstract] Avaliação do Plano Nacional de Controle da Dengue. Cadernos de Saúde Pública [Reports in Public Health] 25(7): 1637-1641. http://dx.doi.org/10.1590/S0102-311X2009000700024

Pichler, V., R. Bellini, R. Veronesi, D. Arnoldi, A. Rizzoli, R. Paolo, L. Domenico, O. Fabrizio, M. S. Carlin, M. Ballardini, E. Antognini, M. Salvemini, E. Brianti, G. Gaglio, M. Manica, P. Cobre, P. Serini, E. Velo, J. Vontas, I. Kioulos, J. Pinto, A. della Torre, and B. Caputo. 2018. First evidence of resistance to pyrethroid insecticides in Italian Aedes albopictus populations 26 years after invasion. Pest Management Science 74(6): 1319-1327. https://doi.org/10.1002/ps.4840

Pleydell, D. R. J., and J. Bouyer. 2019. Biopesticides improve efficiency of the sterile insect technique for controlling mosquito-driven dengue epidemics. Communications Biology 2: 201. https://www.nature.com/articles/s42003-019-0451-1

Poda, S. B., E. Guissou, H. Maïga, N. S. Bimbile-Somda, J. Gilles, J. B. Rayaisse, T. Lefèvre, O. Roux, and R. K. Dabiré. 2018. Impact of irradiation on the reproductive traits of field and laboratory $A n$. arabiensis mosquitoes. Parasites and Vectors 11: 641. https://doi.org/10.1186/s13071-018-3228-3

Puggioli, A., F. Balestrino, D. Damiens, R. S. Lees, S. M. Soliban, O. Madakacherry, M. L. Dindo, R. Bellini, and J. R. L. Gilles. 2013. Efficiency of three diets for larval development in mass rearing Aedes albopictus (Diptera: Culicidae). J. Med. Ent. 50: 819-825. https://doi.org/10.1603/ME13011

Ramchurn, S. K., K. Moheeput, and S. S. Goorah. 2009. An analysis of a short-lived outbreak of dengue fever in Mauritius. Eurosurveil. 14(34): pii=19314. https://doi.org/10.2807/ese.14.34.19314-en

Ranson, H., and N. Lissenden. 2016. Insecticide resistance in African Anopheles mosquitoes: a worsening situation that needs urgent action to maintain malaria control. Trends in Parasitology 32(3)(Special Issue): 187-196. https://doi.org/10.1016/j.pt.2015.11.010

Ranson, H., J. Burhani, N. Lumjuan, and W. C. Black IV. 2010. Insecticide resistance in dengue vectors. TropIKA.net 1(1): 1-12. http://journal.tropika.net/scielo.php?script=sci_arttext\&pid=s2078-86062010000100003\&lng=en

Raviwharmman Packierisamy, P., C. W. Ng, M. Dahlui, J. Inbaraj, V. K. Balan, Y. A. Halasa, and D. S. Shepard. 2015. Cost of dengue vector control activities in Malaysia. The American Journal of Tropical Medicine and Hygiene 93(5): 1020-1027. https://doi.org/10.4269/ajtmh.14-0667

Reeves, R. G., J. A. Denton, F. Santucci, J. Bryk, and F. A. Reed. 2012. Scientific standards and the regulation of genetically modified insects. PLOS Neglected Tropical Diseases 6(1): e1502. https://doi.org/10.1371/journal.pntd.0001502

Reiter, P. 2016. Control of urban Zika vectors: should we return to the successful PAHO/WHO strategy? PLOS Neglected Tropical Diseases 10(6): e0004769 https://doi.org/10.1371/journal.pntd.0004769

(RES) Royal Entomological Society. 2014. Mosquitoes and the Panama Canal. National Insect Week, UK. http:/www.nationalinsectweek.co.uk/news/mosquitoes-and-panama-canal

Salles, T. S., T. da Encarnação Sá-Guimarães, E. S. L. de Alvarenga, V. Guimarães-Ribeiro, M. D. F. de Meneses, P. F. de Castro-Salles, C. R. dos Santos, A. C. do Amaral Melo, M. R. Soares, D. F. Ferreira, and M. F. Moreira. 2018. History, epidemiology and diagnostics of dengue in the American and Brazilian contexts: a review. Parasites and Vectors 11: 264. https://doi.org/10.1186/s13071-018-2830-8

Severo, O. P. 1956. Eradication of the Aedes aegypti mosquito from the Americas. Mosquito News 16(2): 115-121. https://www.cabdirect.org/cabdirect/abstract/19562902063

Sicuri, E., A. Vieta, L. Lindner, D. Constenla, and C. Sauboin. 2013. The economic costs of malaria in children in three sub-Saharan countries: Ghana, Tanzania and Kenya. Malaria Journal 12: 307.

https://doi.org/10.1186/1475-2875-12-307 
Sokhna, C., M. O. Ndiath, and C. Rogier. 2013. The changes in mosquito vector behaviour and the emerging resistance to insecticides will challenge the decline of malaria. Clinical Microbiology and Infection 19(10): 902-907. https://doi.org/10.1111/1469-0691.12314

Soma, D. D., H. Maïga, W. Mamai, N. S. Bimbile-Somda, N. Venter, A. B. Ali, H. Yamada, A. Diabaté, F. Fournet, G. A. Ouédraogo, R. S. Lees, R. K. Dabiré, and J. R. L. Gilles. 2017. Does mosquito mass-rearing produce an inferior mosquito? Malaria Journal 16: 357. https://doi.org/10.1186/s12936-017-2012-8

Stolk, W. A., M. C. Kulik, E. A. le Rutte, J. Jacobson, J. H. Richardus, S. J. de Vlas, and T. A. J. Houweling. 2016. Between-country inequalities in the neglected tropical disease burden in 1990 and 2010, with projections for 2020. PLOS Neglected Tropical Diseases 10(5): e0004560. https://doi.org/10.1371/journal.pntd.0004560

Strugarek, M., H. Bossin, and Y. Dumont. 2019. On the use of the sterile insect release technique to reduce or eliminate mosquito populations. Applied Mathematical Modelling 68: 443-470. https://doi.org/10.1016/j.apm.2018.11.026

Tang, N., J. M. Eisenberg, and G. S. Meyer. 2004. The roles of government in improving health care quality and safety. Joint Commission Journal on Quality and Patient Safety 30(1): 47-55. https://doi.org/10.1016/S1549-3741(04)30006-7

The Economist. 2017. Gene drives. A promising means of pest control meets some evolutionary truths. Resistance is inevitable. 22 July 2017.

(TIS) Technique de l'insecte stérile. 2019. SIT project on mosquitoes in La Réunion. http://tis.re/

Valerio, L., C. M. Collins, R. S. Lees, and M. Q. Benedict. 2016. Benchmarking vector arthropod culture: an example using the African malaria mosquito, Anopheles gambiae (Diptera: Culicidae). Malaria Journal 15: 262. https://doi.org/10.1186/s12936-016-1288-4

Valle, D., D. F. Bellinato, P. F. Viana-Medeiros, J. B. P. Lima, and A. de Jesus Martins Jr. 2019. Resistance to temephos and deltamethrin in Aedes aegypti from Brazil between 1985 and 2017. Mem. Inst. O. Cruz 114: e180544. http://www.scielo.br/pdf/mioc/v114/1678-8060-mioc-114-e180544.pdf

van de Straat, B., A. Hiscox, W. Takken, and T. R. Burkot. 2019. Evaluating synthetic odours and trap designs for monitoring Anopheles farauti in Queensland, Australia. Malaria Journal 18: 299. https://doi.org/10.1186/s12936-019-2923-7

Vargas, R. I., R. F. L. Mau, E. B. Jang, R. M. Faust, and L. Wong. 2008. The Hawaii fruit fly areawide pest management programme, chapter 16, pp. 300-325. In O. Koul, G. W. Cuperus and N. Elliott (eds.), Areawide pest management. Theory and implementation. DOI: 10.1079/9781845933722.0300 http://digitalcommons.unl.edu/cgi/viewcontent.cgi?article=1661\&context=usdaarsfacpub

Vreysen, M. J. B., K. M. Saleh, R. Lancelot, and J. Bouyer. 2011. Factory tsetse flies must behave like wild flies: a prerequisite for the sterile insect technique. PLOS Neglected Tropical Diseases 5(2): e907. https://doi.org/10.1371/journal.pntd.0000907

Wakid, A. M., A. O. Tantawy, A. A. Abdel-Malek, and L. M. El-Gazzar. 1976. Irradiation of the immature stages of the mosquito, Anopheles pharoensis Theob., with ${ }^{60} \mathrm{Co}$. Journal of Applied Entomology 80(1-4): 311-316. https://doi.org/10.1111/j.1439-0418.1976.tb03332.x

Weidhaas, D. E., C. H. Schmidt, and E. L. Seabrook. 1962. Field studies on the release of sterile males for the control of Anopheles quadrimaculatus. Mosquito News 22(3): 283-291. https://archive.org/details/cbarchive_115086_fieldstudiesonthereleaseofster1962

(WHO) World Health Organization. 2009. Dengue guidelines for diagnosis, treatment, prevention and control: new edition. https://apps.who.int/iris/bitstream/handle/10665/44188/9789241547871_eng.pdf?sequence=1

(WHO) World Health Organization. 2012. Global strategy for dengue prevention and control, 2012 2020. https://apps.who.int/iris/bitstream/handle/10665/75303/9789241504034_eng.pdf?sequence=1

(WHO) World Health Organization. 2017a. Global vector control response 2017-2030. 53 pp. https://www.who.int/vector-control/publications/global-control-response/en/ https://apps.who.int/iris/bitstream/handle/10665/259205/9789241512978eng.pdf;jsessionid=577DE2AB19ED196C0B812218BF3BB02B?sequence=1

(WHO) World Health Organization. 2017b. World malaria report 2017. $196 \mathrm{pp}$. https://apps.who.int/iris/bitstream/handle/10665/259492/9789241565523-eng.pdf?sequence=1

(WHO) World Health Organization. 2018. World malaria report 2018. $210 \mathrm{pp}$. https://apps.who.int/iris/bitstream/handle/10665/275867/9789241565653-eng.pdf?ua=1

(WHO/IAEA) World Health Organization/International Atomic Energy Agency. 2020. Guidance framework for testing the sterile insect technique as a vector control tool against Aedes-borne diseases. https://www.iaea.org/sites/default/files/aedes-who-iaea-2020.pdf 
Whyard, S., C. N. G. Erdelyan, A. L. Partridge, A. D. Singh, N. W. Beebe, and R. Capina. 2015. Silencing the buzz: a new approach to population suppression of mosquitoes by feeding larvae doublestranded RNAs. Parasites and Vectors 8: 96. https://doi.org/10.1186/s13071-015-0716-6

(WMP) World Mosquito Program. 2019. The World Mosquito Program is helping to protect the global community from mosquito-borne diseases. http://www.eliminatedengue.com/program

Yahouédo, G. A., L. Djogbénou, J. Saïzonou, B. S. Assogba, M. Makoutodé, J. R. L. Gilles, H. Maïga, K. Mouline, B. K. Soukou, and F. Simard. 2014. Effect of three larval diets on larval development and male sexual performance of Anopheles gambiae s.s. Acta Tropica 132(Suppl.): S96-S101. https://doi.org/10.1016/j.actatropica.2013.11.014

Yamada, H., M. Q. Benedict, C. A. Malcolm, C. F. Oliva, S. M. Soliban, and J. R. L. Gilles. 2012. Genetic sex separation of the malaria vector, Anopheles arabiensis, by exposing eggs to dieldrin. Malaria Journal 11: 208. https://doi.org/10.1186/1475-2875-11-208

Yamada, H., S. M. Soliban, M. J. B. Vreysen, D. D. Chadee, and J. R. L. Gilles. 2013. Eliminating female Anopheles arabiensis by spiking blood meals with toxicants as a sex separation method in the context of the sterile insect technique. Para. Vectors 6: 197. https://doi.org/10.1186/1756-3305-6-197

Yamada, H., M. J. B. Vreysen, J. R. L. Gilles, G. Munhenga, and D. D. Damiens. 2014. The effects of genetic manipulation, dieldrin treatment and irradiation on the mating competitiveness of male Anopheles arabiensis in field cages. Malaria J. 13: 318. https://doi.org/10.1186/1475-2875-13-318

Yamada, H., M. J. B. Vreysen, K. Bourtzis, W. Tschirk, D. D. Chadee, and J. R. L. Gilles. 2015. The Anopheles arabiensis genetic sexing strain ANO IPCL1 and its application potential for the sterile insect technique in integrated vector management programmes. Acta Tropica 142: 138-144. https://doi.org/10.1016/j.actatropica.2014.11.013

Zabalou, S., M. Riegler, M. Theodorakopoulou, C. Stauffer, C. Savakis, and K. Bourtzis. 2004. Wolbachia-induced cytoplasmic incompatibility as a means for insect pest population control. Proceedings of the National Academy of Sciences of the United States of America 101(42): 1504215045. https://doi.org/10.1073/pnas.0403853101

Zacarés, M., G. Salvador-Herranz, D. Almenar, C. Tur, R. Argilés, K. Bourtzis, H. Bossin, and I. Pla. 2018. Exploring the potential of computer vision analysis of pupae size dimorphism for adaptive sex sorting systems of various vector mosquito species. Parasites and Vectors 11(Suppl. 2): 656. https://doi.org/10.1186/s13071-018-3221-X

Zhang, D., X. Zheng, Z. Xi, K. Bourtzis, and J. R. L. Gilles. 2015a. Combining the sterile insect technique with the incompatible insect technique: I-impact of Wolbachia infection on the fitness of triple- and double-infected strains of Aedes albopictus. PLOS ONE 10(4): e0121126. https://doi.org/10.1371/journal.pone.0121126

Zhang, D., R. S. Lees, Z. Xi, J. R. L. Gilles, and K. Bourtzis. 2015b. Combining the sterile insect technique with Wolbachia-based approaches: II-a safer approach to Aedes albopictus population suppression programmes, designed to minimize the consequences of inadvertent female release. PLOS ONE 10(8): e0135194. https://doi.org/10.1371/journal.pone.0135194

Zhang, D., R. S. Lees, Z. Xi, K. Bourtzis, and J. R. L. Gilles. 2016. Combining the sterile insect technique with the incompatible insect technique: III-robust mating competitiveness of irradiated triple Wolbachia-infected Aedes albopictus males under semi-field conditions. PLOS ONE 11(3): e0151864. https://doi.org/10.1371/journal.pone.0151864

Zhang, D., Y. Li, Q. Sun, X. Zheng, J. R. L. Gilles, H. Yamada, Z. Wu, Z. Xi, and Y. Wu. 2018. Establishment of a medium-scale mosquito facility: tests on mass production cages for Aedes albopictus (Diptera: Culicidae). Parasites and Vectors 11: 189. https://doi.org/10.1186/s13071-018-2750-7

Zheng, M. L., D. J. Zhang, D. D. Damiens, H. Yamada, and J. R. L. Gilles. 2015. Standard operating procedures for standardized mass rearing of the dengue and chikungunya vectors Aedes aegypti and Aedes albopictus (Diptera: Culicidae) - I - egg quantification. Parasites and Vectors 8: 42. https://doi.org/10.1186/s13071-014-0631-2

Zheng, X., D. Zhang, Y. Li, C. Yang, Y. Wu, X. Liang, Y. Liang, X. Pan, L. Hu, Q. Sun, X. Wang, Y. Wei, J. Zhu, W. Qian, Z. Yan, A. G. Parker, J. R. L. Gilles, K. Bourtzis, J. Bouyer, M. Tang, B. Zheng, J. Yu, J. Liu, J. Zhuang, Z. Hu, M. Zhang, J. T. Gong, X. Y. Hong, Z. Zhang, L. Lin, Q. Liu, Z. Hu, Z. Wu, L. A. Baton, A. A. Hoffmann, and Z. Xi. 2019. Incompatible and sterile insect techniques combined eliminate mosquitoes. Nature 572: 56-61. https://doi.org/10.1038/s41586-019-1407-9 https://www.nature.com/articles/s41586-019-1407-9

Zwizwai, R. 2017. Infectious disease surveillance update. The Lancet Infectious Diseases 17(3): 270. https://doi.org/10.1016/S1473-3099(17)30065-8 